\title{
Fatigue Tests on UHM-CFRP Strengthened Steel Plates with Central Inclined Cracks under Different Damage Levels
}

\author{
N.J. Aljabar \& X.L. Zhao* \\ Department of Civil Engineering, Monash University, Clayton, VIC 3800, Australia \\ (*corresponding author, email: ZXL@ monash.edu)
}

\author{
R. Al-Mahaidi \\ Faculty of Engineering and Industrial Sciences, Swinburne University of Technology, Melbourne, \\ Australia \\ E. Ghafoori \& M. Motavalli \\ Empa, Swiss Federal Laboratories for Materials Science and Technology, Dübendorf, Switzerland \\ Y.C. Koay \\ VicRoads, VicRoads, 60 Denmark Street, Kew, VIC 3101, Australia
}

\begin{abstract}
Ageing structures and metallic bridges, in particular, are vulnerable to fatigue failure due to having sensitive fatigue details. The literature on upgrading these structures highlights the efficiency of tensile (mode I) fatigue strengthening using carbon fibre reinforced polymer (CFRP) composites. However, cracks or defects are often oriented to the loading angle, which develops mixed-mode (I+II) conditions that govern crack propagation. Therefore, the efficacy of mode-I fatigue strengthening needs to be evaluated under such conditions and at different stages of the fatigue service life. This paper extends the current understanding of fatigue strengthening with CFRP from mode I loading to the case of mixed-mode (I+II) with different initial damage level. CRFPstrengthened steel plates were produced with six loading angles between $90^{\circ}$ and $10^{\circ}$ and three damage levels. Test results revealed that the mixed-mode crack propagation curves of steel plates strengthened at different stages of their fatigue life were approximated by the same crack growth curve in pure tensile mode by utilizing the shifting concept. Mixed mode modification factor was derived from test results of 36 specimens to predict the fatigue life of CFRP-strengthened steel plates initially inclined cracked with various degrees of damage.
\end{abstract}


KEYWORDS: Fatigue; Inclined cracks; Initial crack length, Damage degree, Ultra-high modulus CFRP laminate; CFRP strengthening; Steel plate

\section{NOMENCLATURE}

$\beta \quad$ Loading angle

$\mathrm{a}_{\mathrm{o}} \quad$ Initial crack length

Number of cycles

$N_{m} \quad$ Number of cycles under mixed mode (I+II) loading

$N_{T} \quad$ Total fatigue life of the CFRP-strengthened specimens with different lengths of initial inclined cracks

$N_{\left(\beta=90^{\circ}\right)} \quad$ Number of cycles under mode I loading

SIF Stress Intensity Factor

$f_{(\beta)} \quad$ Mixed mode modification factor 


\section{INTRODUCTION}

The design philosophy of most standard codes aims to ensure that all the structural components are fully integrated by controlling possible existing flaws limits lower than the detection limit of the inspection methods. When the defect exceeds that limit, an inspection plan is designed, including the inspection interval based on the simulated crack extension [1]. Therefore, the serviceability of structural elements is continuously assessed and controlled with closer inspection intervals for larger defects. However, the crack might be missed in one or more inspections, and may not be detected before propagating for a stage of the service life of the damaged component. When the crack is eventually detected, depending on its length, either new inspection intervals is setup or the element is repaired.

The main aim of strengthening defected metal elements is to alleviate the stress intensity on the base plate by transferring the load between the attached components. The efficacy of the load transfer mechanism depends on both the mechanical properties (added stiffness) of the patched elements and the attachment method. Conventional repair methods, such as welded or bolted plates, often increase the stiffness of the repaired components but create extra dead load. What makes it worse is that the conventional attachment methods induce stress concentrations near the patched area [2]. In contrast, innovative materials such as fibre reinforced polymer (FRP) offer promising alternatives to overcome such conditions after repair [3-5]. Because they have greater stiffness, CFRP composites have gained increased attention for the strengthening of steel structures $[6,7]$.

A series of fatigue tests combined with numerical analysis was carried out at the Swiss Federal Laboratories for Material Science and Technology (Empa) on steel beams with cracked tension flanges patched with pre-stressed CFRP plates [8-14]. For cracked steel plate, the pre-stressing CFRP technique had already been applied by Bassetti et al. [15]. These researchers found that the fatigue life of the cracked plates was increased by 16 times after being pre-stressed by CFRP (E=216GPa, 
$\mathrm{t}=1.4 \mathrm{~mm}$ ). Colombi et al. $[16]$ conducted a numerical study on the same specimens. They found that utilizing CFRP plates with high tensile stiffness in the pre-stressing technique before being bonded to the damaged components slowed the fatigue crack growth rate by reducing the stress ratio and promoting crack closure. However, in practice, the application of pre-stressed CFRP composites on steel plates is not a direct process, as an anchorage system needs to be installed at the ends of the plates [2]. Furthermore, the pre-stressing forces induce stress concentrations at the plate ends, and debonding failure is highly expected.

Therefore, a large number of the studies on strengthening steel plates have adopted the adhesivelybonded method. The scope of these studies has covered the effect of the mechanical properties of the attached composite, attachment methods, and patching configurations. Different specimens, such as centrally and edge-cracked plates were strengthened and evaluated under tension fatigue tests. Experimental results revealed that increasing the tensile stiffness of the CFRP patching, i.e. by adopting the double-sided over the single-sided strengthening method $[17,18]$, or using higher Young's modulus material [19], improved the load-transfer action between the adherents. However, it is not always possible to approach both sides of the defected area, especially in multi-plated components in old bridges. Therefore, strengthening methods may be limited to the single patching method of the CFRP. The necessity to understand the fracture parameters in such an asymmetric strengthening method and their effect on fatigue life have attracted the interest of many researchers [20-23].

As highlighted earlier, since defects or cracks may be detected at different lengths, CFRP strengthening can be applied at various stages of the structure's service lifetime. In this context, the efficiency of mode I fatigue strengthening has been evaluated for various damage degrees by many researchers. For example, Yu et al. [24] analyzed the fatigue performance of a CFRP strengthening system on the initial crack length using double-sided reinforcement. Different lengths of cracks 
emanating from a central hole were introduced to simulate damage levels of $2 \%, 10 \%$, and $30 \%$. The test results showed an efficient performance of the CFRP strengthening of specimens with a damage degree of $30 \%$ compared with $2 \%$, whereas it was insignificant for specimens with mild damage $(10 \%)$. This reduction in the fatigue performance was explained by the premature debonding of the composite plates for these specimens. The study was extended in [25] for wider crack length ratios (2\%-40\%) with a focus on utilizing UHM CFRP and normal modulus CFRP plates with different patching schemes. Due to the significant increase in the stiffness ratio of the composite, the fatigue life improvement ratio was raised sharply compared with the earlier study. Subsequently, the effect of the damage level on the crack propagation was investigated further using the boundary element method [26], finite element method [27] and experimental testing [28].

It should be pointed out that all the research mentioned above has been conducted utilizing the composite material only in mode I fatigue strengthening. In fact, fatigue sensitive details in ageing bridges are often exposed to load conditions that develop a mixed-mode state that governs the fracture mechanism. Mixed mode fatigue of steel alone has been studied in the literature [e.g. 29]. However there is very limited information on the influence of CFRP strengthening on the mixed mode fatigue [30-33]. Recently, an experimental study was carried out by Aljabar et al. [34] on steel plates notched with a range of inclined cracks to simulate mixed-mode loading conditions (I+II) at the crack tip. All test specimens were strengthened with one layer of UHM-CFRP on a single side. The results showed that the fatigue life increases proportionally with the mode-mixity (shear-/tensile-stress intensity factor) at the crack tip. The study also demonstrated that the mixed-mode crack-propagation curves could be approximated by mode I crack growth curves.

However, it is important to note that the study [34] was conducted on steel plates with short cracks only. Therefore, in the present paper, the test program was extended to investigate the effect of damage level on fatigue behaviour of the strengthened steel plates with inclined initial cracks. For 
this purpose, inclined cracks in the base plates were introduced with different initial crack lengths to simulate a range of damage degrees. The damage level represents the ratio of the crack starter emanating from the central hole to the plate's width. Two damage degrees of $10 \%$ and $30 \%$ were investigated under constant fatigue loading, and different loading angles between $90^{\circ}-10^{\circ}$, then compared to the preliminary study of the damage level of $2 \%$. This paper constitutes part of a large research program on the CFRP strengthening of metallic bridges under mixed-mode loading (I+II) at Monash University in collaboration with Swinburne University of Technology, and the Swiss Federal Laboratories for Materials Science and Technology (Empa), which is sponsored by the Australian Research Council, VicRoads and S\&P Clever Reinforcement Company AG.

\section{EXPERIMENTAL PROGRAM}

A total of 36 specimens were designed and tested in the Civil Engineering Laboratory at Monash University in Melbourne, Australia. The test specimens were divided into two groups with different initial crack lengths. For each group, twelve centrally-cracked steel plates were strengthened with CFRP, and six un-strengthened cracked plates were prepared as control specimens. All steel plates were artificially notched from a $5 \mathrm{~mm}$ central hole with different crack inclination angles and different initial crack lengths, to investigate the effect of the combined action of stresses at the crack tip on the fatigue life and CFRP strengthening performance. This procedure simulated the case when the strengthening system is applied at different stages of the fatigue service lives of the steel elements. Two strengthening configurations were applied in this study for each crack-inclined specimen.

\subsection{Material properties}

Table 1 shows the measured properties of the components of the strengthening system. The properties of the steel plates were determined from tensile coupon tests according to AS1391[35], whereas those 
of the composite and adhesive material were the same as that reported in $[19,36]$. The steel plates and the unidirectional CFRP laminates had uniform, cross-sections of about $90 \times 10 \mathrm{~mm}$, and $50 \times 1.5 \mathrm{~mm}$, respectively. MBrace 460/1500, which is referred to as ultra-high modulus (UHM), was utilized for reinforcing the steel plates. It has a tensile strength and Young's modulus of 1500MPa and 460GPa, respectively based on the manufacturer's tests. The two-component adhesive, Araldite $420 \mathrm{~A} / \mathrm{B}$, was utilized for bonding the components of the strengthening system.

\subsection{Preparation of the CFRP-strengthened specimens}

The mixed-mode loading condition at the crack tip is usually simulated by changing the loading angle at the crack tips, i.e. either by altering the path of the external force of central tensile cracked specimens, or the crack orientation of uniaxially loaded specimens. The latter method was adopted in this study for simplicity. Steel plates with uniform cross-sections were artificially notched using an electric discharge machine (EDM), with a $5 \mathrm{~mm}$ central hole open to two crack starters (slits). The crack starters were oriented at different degrees $\left(90^{\circ}-10^{\circ}\right)$ to investigate the effect of the mixed-mode loading condition (I+II). The geometry and the dimensions of the test specimens are illustrated in Figure 1. The effect of the crack orientation of CFRP-strengthened specimens with short crack length $\left(0.9 \mathrm{~mm}\right.$ crack starter) corresponding to damage level $\left(2 \mathrm{a}_{\mathrm{o}} / \mathrm{W}\right)$ of $2 \%$, was reported in a preliminary paper by the authors [34]. The application of the patch composite at an advanced stage of the service life of the steel elements is presented in this paper, i.e. steel plates with damage level of $10 \%$, and $30 \%$ corresponding to crack lengths of $4.5 \mathrm{~mm}$, and $13.5 \mathrm{~mm}$.

A single-sided repair method was adopted in the test program, and for strengthening purposes, two patching configurations were applied, i.e. the laminates covered either the whole (configuration A) 
or part (configuration D) of the crack area, as shown in Figure 2. The tensile stiffness ratio of the former was just above twice that of the latter.

The strengthened surface of the steel plates was sand-blasted first for better bonding with the CFRP laminate [37]. The abraded surface was then cleaned of contaminants using acetone solution. The two components of Araldite 420 were mixed based on the recommended dosage and spread evenly on the patching area using a brush. The CFRP plates were then positioned as shown in Figure 2. The adhesive thickness was controlled at $0.5 \mathrm{~mm}$, using the procedure reported in [19].

\subsection{Fatigue testing procedure}

The fatigue testing set-up and the testing procedure followed were the same as those detailed in [34]. The steel plates were subjected to a constant cyclic amplitude before and after being strengthened with the composite patch. An Instron 8802 servo-hydraulic testing machine with a maximum cyclic load of $\pm 250 \mathrm{kN}$ was utilized in the fatigue tests. The sinusoidal cyclic load varied between $150 \mathrm{MPa}$ and $15 \mathrm{MPa}$, corresponding to about $30 \%$ of the ultimate tensile stress of the steel plates. A few specimens did not fail under this loading. Therefore, the maximum testing stress was increased to just below $40 \%$ of the steel's ultimate tensile stress. The fatigue tests were carried out within a $20 \mathrm{HZ}$ frequency and 0.1 load ratio.

\subsection{Measurement of crack length}

The crack propagation along fractured surface was monitored and measured using the beach marking method. A schematic view of the procedure adopted for measuring the crack length is shown in Figure 3. Due to the bending effect of the single-sided repair, the crack front adopted an asymmetric shape as it grew faster on the free surface than the strengthened surface of the steel plates. The measured 
crack length on the free surface was adopted in the crack propagation curves. Using a steel ruler, the distance from the initial crack tip to the crack front end on the free surface was first measured for all beach marks on the fracture surface (i.e. $a_{1}, a_{2}$, and $a_{i}$ ). The average value of the measured lengths on both sides of the central hole was then calculated. Next, the equivalent crack length of the kinked crack was calculated (e.g. $\overline{a_{1}}, \overline{a_{2}}$, and $\overline{a_{l}}$ ) representing the direct distance from the central hole to the crack tip at the free surface of the strengthened plates. The number of cycles corresponding to the measured crack lengths was then determined in producing the $a-N$ curves.

\section{FATIGUE LIFE IMPROVEMENT RATIO}

The combined action of the tensile and shear stresses at the crack tip was investigated in this study under different degrees of damage of the cracked steel components after being strengthened with CFRP plates on a single side. The test results are summarized in Tables 2 to 4 for specimens with damage levels of $2 \%, 10 \%$, and $30 \%$, respectively. The results for the $2 \%$ damage level were obtained from earlier work by the authors [34]. Therefore, the symbols for the tested specimens were kept the same, including the damage degree of each group. The symbols for the tested specimens represent the strengthening state, i.e. either un-strengthened specimens (US) or single-sided strengthened specimens with configuration A, (SHA) or configuration D (SHD). Following is the damage degree, and finally the crack orientation. The loading level, fatigue life, fatigue improvement factor, equivalent fatigue life under test loading, and the number of cycles under mixed-mode loading are presented in the tables above. The fatigue loading level is the percentage of the maximum applied stress to the tensile yield stress of the steel plates. The recorded number of cycles until the crack grows through the whole plate's width stands for the fatigue life, whereas the ratio of the fatigue life of the CFRP-strengthened to un-strengthened specimens represents the fatigue improvement factor. As some of the test specimens failed at different loading levels, their fatigue lives were converted to 
the equivalent number of cycles at the test loading, as presented in Tables 2-4. The number of cycles under mixed-mode loading $\left(N_{m}\right)$ represents the difference between the fatigue life of specimens exhibiting mixed-model loading $\left(\beta<90^{\circ}\right)$ and that of those showing pure mode-I loading $\left(\beta=90^{\circ}\right)$.

In general, the fatigue behaviour was similar for different degrees of damage. A noticeable increase in the number of cycles was recorded for cracked plates with smaller loading angles. This trend can be explained by the reduction of the tensile stress intensity factor for smaller crack angles, which is most significant for specimens of $\beta=10^{\circ}$. Similar to steel plates with short initial crack length (damage degree equal to $2 \%$ ), these specimens did not fail under the test loading, even with increased crack lengths (damage degree equal to $10 \%$ ). In contrast, they failed when the fatigue loading level was raised to $0.6 f y$. However, when the initial crack length was greater, more than twice the former, the specimens failed under the designed load. This could be attributed to the fact that higher T-SIF for longer cracks controls the crack propagation after a shorter stage of mixed-mode condition. To unify the test results from different loading levels, the fatigue life of specimens which failed under a higher stress range $\left(N_{2}\right)$ was converted to the equivalent fatigue life under the stress range of the designed test loading $\left(N_{l}\right)$ by using Eq. 1 , where $\Delta \sigma_{1}$, and $\Delta \sigma_{2}$ represent the stress range at the test loading level (046fy) and the increased loading level (0.6fy) respectively, whereas the power $\mathrm{n}$ represents the slope of the $S-N$ curve of a typical steel connection, which is assumed to be $3[38]$ :

$$
\frac{N_{1}}{N_{2}}=\left(\frac{\Delta \sigma_{2}}{\Delta \sigma_{1}}\right)^{n}
$$

As expected, the steel plates repaired with larger laminate cross-sections gained higher fatigue strength and longer fatigue life, whatever the crack orientation or the damage level. The average fatigue improvement factor was higher for CFRP-strengthened steel plates with longer crack lengths for different patching arrangements. However, partially-patched plates with moderate damage (10\%) 
had lower improvement factors than plates with mild damage (2\%). This could be attributed to the inadequate quality of the fabricated specimens, or an earlier debonding, as reported in [24]. Furthermore, it was evident that the specimens that failed under higher load showed less improvement from the bonded patches. In general, compared to the first set of specimens with the shortest crack lengths $(2 \%)$, there was almost no change in the fatigue life improvement factor for the second set with a larger crack length ratio $\left(2 \mathrm{a}_{0} / \mathrm{W}=10 \%\right)$. Conversely, the improvement factor increased by almost $31 \%$ and $25 \%$ for configuration $\mathrm{A}$, and D respectively, when the steel plates were strengthened after experiencing severe damage of (30\%). It should be noted that the fatigue life improvement factor presented in Tables 2-4 did not consider the effect of the initial crack length of unrepaired specimens under different damage level, as will be discussed later. Regarding the strengthening scheme performance of the tested specimens, the average fatigue improvement factor of partiallystrengthened specimens (SHD) was around $70 \%$ of that of the fully- strengthened.

A similar test program was conducted at Monash University only on tensile cracked steel plates $\left(\beta=90^{\circ}\right)$ strengthened partially (configuration D) by the double-sided repair method [25]. With the same materials and test loadings, the fatigue performance of steel plates partially strengthened with CFRP using the single-sided method under pure tensile load (mode I) was 50\%, $44 \%$, and $33 \%$ of that of the double-sided CFRP-strengthened plates with damage levels of $2 \%, 10 \%$, and $30 \%$ respectively. It is obvious that the application of the composite patch on only one side of the cracked components shows less fatigue improvement for longer initial crack length.

\section{CRACK PROPAGATION CURVES}

The outcomes of the preliminary tests on $2 \%$ damaged plates revealed the shifting phenomenon in the mixed-mode crack propagation curves for a different range of mode-mixity. This trend showed that the mixed-mode crack propagation curves of all specimens of $\beta<90^{\circ}$ experienced almost exactly 
the pure mode I crack growth $(\overline{a b})$ of specimens of $\beta<90^{\circ}$ after completing a stage of the total fatigue life under mixed-mode conditions, as illustrated in Figure 4. Moreover, the shifting amount was found to be inversely proportional to the loading angles.

Interestingly, apart from the shifting degree, the fatigue behaviour was very similar when the CFRP composites were applied at different stages of the fatigue lives of the cracked plates, namely steel plates under moderate and severe damage levels as presented in Figures 5-10. Starting with the former case, the fatigue lives of specimens of $\beta=10^{\circ}$ that failed under higher stress ranges were converted to the equivalent number of cycles under the test loading. Then, the crack propagation curves of steel plates with different crack angles were plotted together for two patching configurations, as presented in Figures 5-7. It should be noted that as specimens of $\beta=10^{\circ}$ failed only at stress ranges higher than the designed fatigue loading, their crack propagation curves in Figures 57 are conservative for the test loading, and they are presented to highlight the fatigue behaviour under a wide range of mode-mixity. For specimens with a crack length ratio of $30 \%$, the $a-N$ curves are presented in Figures 8-10. It is clear that the mixed-mode influence translates into a shift in crack propagation curves corresponding to the effect of the combined action of stresses at the crack tips of the inclined cracks.

When steel plates with damage higher than $2 \%$ (longer initial crack lengths) were strengthened with composite laminates, the shifting amount decreased proportionally with increasing initial crack length. This is caused by the dominance of the tensile stresses on the crack propagation rate of longer cracks. Compared to the four groups of crack growth behaviour observed with smaller damage levels, the mixed-mode crack propagation in moderate and highly damaged plates is noticeable only with higher combined actions of stresses (smaller loading angles). In the latter, the crack growth curves can be divided into the following zones: (1) specimens with cracked angles larger than $30^{\circ}$, which are almost merged in one curve, (2) specimens with crack angle $30^{\circ}$ shifted slightly away from the 
first region, and (3) specimens with the least T-SIF in the group shifted far away with higher fatigue life. This behaviour applied for all samples, whatever the strengthening status or damage level.

\section{EFFECT OF CRACK ORIENTATION ON THE CFRP-STRENGTHENING PERFORMANCE}

It is well known that the fatigue life and the fatigue crack propagation rate are controlled mainly by the tensile stress intensity factor at the crack tip, which is defined as the crack driving force. For steel components with randomly-oriented cracks, the crack driving components are a function of the crack inclination degree, or more specifically, the loading angles. Therefore, as the loading angle decreases, and then the mode-mixity ratio increases, the T-SIF component drops, and the crack propagation delays. In other words, the shear stress intensity factor dominates the fatigue behaviour alone or combined with the tensile component. It is believed that the crack grows in this zone under shear mode, although the crack propagation length is not visible [39].

Under different damage degrees, the test results showed the effect of the mixed-mode loading in delaying crack initiation, but only for a part of the fatigue life corresponding to the magnitude of the T-SIF and S-SIF components. Furthermore, the mixed-mode phase was more pronounced in the mixed-mode crack propagation curves for CFRP-strengthened plates in the near-threshold zone (2\% damage). As the crack length increases, the local tensile stress component at the crack tip becomes larger, and the mixed-mode fatigue behaviour becomes less pronounced. This explains the reduction in the shifting degree (crack orientation influence) when the composite laminates are applied at a late stage of crack propagation. It should be noted that the observed behaviour was similar before and after applying the CFRP laminates. 


\section{EFFECT OF DAMAGE LEVEL ON CFRP-STRENGTHENING PERFORMANCE}

The influence of initial crack length on the mode I fatigue performance of central or edge tensile cracked specimens strengthened with CFRP strips has been reported in the literature [25, 28]. However, there are different ways to study this effect in mixed-mode problems, i.e. by assessing either the damage level effect universally for the entire range of crack lengths and angles or separately for each loading angle for different crack lengths. Figures 11-14 show the CFRP-strengthening efficacy for two schemes when the degree of initial damage varies between $2 \%-30 \%$. The fatigue improvement factor for the tested specimens (SHA and SHD) showed on the vertical axis, whereas the damage ratio presented on the horizontal axis. The general trend of the measured fatigue performance of the test specimens is presented in Figures 11 and 12, whereas that for each loading angle is shown in Figures 13 and 14. For comparison purpose and to include the effect of initial crack length of each loading angle, it assumed that the specimens that ran out having a fatigue life of 10 million based on BS 7608 [38]. It is evident that the higher the damage level, the more pronounced the increase in the fatigue life. However, Figures 13 and 14 do not show any specific trend within each set of loading angles for each damage level. The number of cycles counted after strengthening of the severely damaged plates was extended by an average of almost 2.2 and 2 for different crack inclination angles of configurations A and D, respectively. In contrast, the fatigue behaviour of steel plates with smaller damage degrees of $10 \%$ was similar to the $2 \%$ case. Yu et al. [24] reported similar fatigue behaviour for the same specimens with similar damage levels but with tensile cracks. This was attributed to early debonding of the composite plates.

As presented earlier, the cracked specimens were artificially provided with three different crack starter lengths of $0.9 \mathrm{~mm}, 4.5 \mathrm{~mm}$ and $13.5 \mathrm{~mm}$ to investigate the effect of $2 \%, 10 \%$, and $30 \%$ damaged plates, respectively on the repair system. In practice, the crack development from the short initial 
length $(0.9 \mathrm{~mm})$ to a longer length $(4.5 \mathrm{~mm}$, and $13.5 \mathrm{~mm})$ accounts for a certain number of cycles. To underline the importance of the damage level on the fatigue life of the strengthening system, the initial number of cycles which accounted for the crack growth $(\mathrm{Ni})$ was considered in measuring the fatigue performance, as shown in Figures 15-18. The general trend of strengthening efficiency was completely reversed with a marginal change in the enhancement of the composite. In this regard, the smaller the damage level, the more efficient the CFRP strengthening system.

\section{FATIGUE LIFE PREDICTION USING MIXED-MODE MODIFICATION FACTOR}

Fatigue crack propagation curves for all the tested specimens exhibited similar behaviour for different initial inclined crack lengths. More precisely, the shifting phenomenon highlighted earlier in specimens with smaller degrees of damage did not change within a wider range of damage levels. Therefore, similarly to the former case, a mixed-mode modification factor (MMMF, or $f_{\beta}$ ) was derived from the test data of specimens of different degrees of damage, namely $10 \%$, and $30 \%$. The whole range of $f_{\beta}$ values can be utilized in estimating the fatigue life of initially inclined cracked specimens strengthened with CFRP from the fatigue life of central tensile cracked specimens. In Eq.

2, $f_{\beta}$ stands for the ratio of the number of cycles under mixed-mode loading $\left(N_{m}\right)$ to that under modeI $\left(N_{\beta=90^{\circ}}\right)$. Using the derived factor, the total fatigue life $\left(N_{T}\right)$ of the CFRP-strengthened specimens with different lengths of initial inclined cracks can be estimated from the following equations:

$$
f_{(\beta)}=\frac{N_{m}}{N_{\beta=90^{\circ}}}
$$

$$
N_{T}=N_{\beta=90} \times\left(1+f_{(\beta)}\right)
$$


Tables 5 and 6 summarize the calculated values for Eq. 2 from the test results of damage levels 10\%, and $30 \%$, respectively. From these data, it appears that the calculated ratios of the mixed-mode modification factor were mostly higher for the specimens with the greatest damage which failed within the test loading. However, this could be attributed to the reduction in the number of cycles of pure mode I specimens with larger crack length ratios, rather than the increase in the $N_{m}$. The data for the $2 \%$ case for loading angles $90^{\circ}-30^{\circ}$ were presented in different ways in [34]. The MMMF values were calculated either accurately using the non-linear fitting from Eq.4, or by a linear approximation from Eq.5 as follows:

$f_{(\beta)=} 0.0394+\frac{711}{\left(1+\exp \left(\frac{\beta+0.1424}{6.943}\right)\right)}$

$$
\left.\begin{array}{c}
f_{(\beta)}=9-\frac{8}{15}(\beta-30) \text { for } 30^{\circ} \leq \beta<45^{\circ} \\
f_{(\beta)}=1-\frac{0.8}{15}(\beta-45) \text { for } 45^{\circ} \leq \beta<60^{\circ} \\
f_{(\beta)}=0.2-\frac{0.1}{15}(\beta-60) \text { for } 60^{\circ} \leq \beta<90^{\circ}
\end{array}\right\}
$$

Similarly, in the present paper, a fitting curve for the measured values of $f_{\beta}$ for both $10 \%$, and $30 \%$ cases and for $\beta<90^{\circ}$ is presented in Eq. 6, using the upper bound of the data of both sets. It should be noted that this equation under-estimates the calculated values of $f_{\beta}$ for $\beta \geq 45^{\circ}$.

$$
f_{(\beta)=} 0.172+\frac{10090}{\left(1+\exp \frac{(\beta+43)}{8.37}\right)}
$$


However, by using the upper bound of the average values of $f_{\beta}$ listed in Tables 5 and 6 , the experimental values of MMMF can also be approximated by a linear equation, as expressed in Eq. 7 for both sets of specimens. The measured values of the MMMF from Eq. 2 and Eq. 4 to Eq. 7 are presented in Figure 19. Obviously, the MMMF covers four regions for different crack length ratios of $10 \%$ and $30 \%$, i.e. from $10^{\circ}$ to $30^{\circ}$, from $30^{\circ}$ to $45^{\circ}$, from $45^{\circ}$ to $60^{\circ}$, and from $60^{\circ}$ to $90^{\circ}$. Compared with the smallest degree of damage, Figure 19 shows a wider range of the mode-mixity ratios due to the increase in crack lengths and then the T-SIF for smallest loading angle that failed eventually under the test loading. It is obvious that the mixed-mode modification factor was almost consistent for un-strengthened and strengthened specimens and even for different strengthening schemes for most of the covered range. However, the values of $f_{\beta}$ for specimens that did not fail under test loading but did under higher loads, were susceptible to different strengthening schemes. The might be attributed to the effect of the unstable crack propagation under higher fatigue loading.

$$
\left.\begin{array}{l}
f_{(\beta)}=18-\frac{16.25}{20}(\beta-10) \text { for } 10^{\circ} \leq \beta<30^{\circ} \\
f_{(\beta)}=1.75-\frac{1.12}{15}(\beta-30) \text { for } 30^{\circ} \leq \beta<45^{\circ} \\
f_{(\beta)}=0.63-\frac{0.37}{15}(\beta-45) \text { for } 45^{\circ} \leq \beta<60^{\circ} \\
f_{(\beta)}=0.26-\frac{0.13}{15}(\beta-60) \text { for } 60^{\circ} \leq \beta<90^{\circ}
\end{array}\right\}
$$

\section{EXPLANATION OF THE SHIFTING PHENOMENON IN CFRP-STRENGTHENED STEEL PLATES NOTCHED WITH INCLINED CRACKS}

In this paper, the mixed-mode crack propagation curves reveal the mode-mixity effect in terms of the shifting phenomenon. The higher the mode-mixity ratio, the larger the shifting from mode I, and the longer fatigue life. From Figure 19, it is evident that this effect was nearly consistent within each 
degree of mode-mixity and damage level for all the specimens with or without the CFRP. Therefore, in this discussion the focus is on explaining the mixed-mode effect on a typical specimen with a range of crack angles, which could be applied to each degree of damage and strengthening condition (strengthened and un-strengthened specimens). There are different ways to clarify the proportional effect of crack angle/mode-mixity on the crack propagation curves, as follows:

1. For inclined cracked specimens, the T-SIF could be defined as the crack driving force and the $\mathrm{S}-\mathrm{SIF}$ as the impedance for this force. More precisely, for any increase in S-SIF, there is a decrease in the T-SIF and then delays in the crack initiation. This highlights the direct effect of loading angle on T-SIF and the fatigue life. This effect is proportional to the sine squared of the loading angle, which clearly indicates the shifting in mixed-mode (I+II) crack propagation curves. The loading angle also reflects the degree of mode-mixity, as it influences both T-SIF, and S-SIF. This can be clarified using the general SIF formula for steel plates with inclined cracks as follows [40]:

$$
\begin{aligned}
& T-S I F=S I F_{\beta=90^{\circ}} \times \sin ^{2}(\beta) \\
& S-S I F=S I F_{\beta=90^{\circ}} \times \sin (\beta) \cos \beta
\end{aligned}
$$

2. The mixed-mode (I+II) effect can be illustrated in the stress analysis of the test specimens for the whole range of loading angles. Simplified 2-D analysis has been conducted for unstrengthened specimens for the same reason highlighted in point 1 . The shifting in crack propagation curves can be easily understood from the combined action of tensile and shear stresses at the crack tip for different crack angles. Figure 20 shows the stress combination for crack angles between $90^{\circ}-10^{\circ}$. While the T-SIF dropped considerably over the entire range of 
crack angels, the S-SIF showed an increase with a less amount for crack angles less than $45^{\circ}$. Therefore, the effective SIF followed the same trend of T-SIF. The proportional drop in the SIF effect reflects the range of shifting degrees in mixed-mode crack propagation curves, i.e. T-SIF for $\beta=30^{\circ}$ dropped to $10 \%$ of that of mode-I, while that of $\beta=10^{\circ}$ indicated that the crack did not open under the test loading. This accurately explains the significant shift of $\beta=30^{\circ}$ crack growth curves from mode I, and the reason for 'run-out' results of $\beta=10^{\circ}$. It is important to highlight the fact that what is applied on un-strengthened specimens, is applied on specimens with different strengthening schemes in terms of interpreting the shifting phenomenon apart from the degrees of shift. Similarly, the mode mixity ratio introduced in Figure 21 shows the upward trend over the covered range of the loading angles. The ratio increases significantly once the inclined angle is less than 45 degrees. It should be noted that in future work, the authors will investigate the definition of the mixed-mode phases and the turning point between these phases, as revealed by mixed crack propagation curves by using numerical analysis such as the boundary element method incorporating fracture mechanics.

\section{CONCLUSIONS}

Mixed-mode (I+II) crack propagation was investigated experimentally on a total of 36 steel plates with inclined cracks under tension fatigue loading. The steel plates were notched with different lengths of two crack starters emanating from a central hole to simulate two degrees of damage levels, i.e. $10 \%$, and $30 \%$. The cracks were oriented at six degrees $\left(90^{\circ}-10^{\circ}\right)$ to introduce a range of modemixity. The CFRP plates were applied on 24 specimens with different damage levels, whereas 12 specimens acted as control specimens. Based on the test results, the following conclusions can be drawn. 
1. For different loading angles, the fully-strengthened specimens (SHA) showed an average increase in fatigue life of up to 2.4 and 3 times that of the un-strengthened specimens for damage levels of $10 \%$, and $30 \%$ respectively. In general, the average fatigue improvement ratio of partially-strengthened specimens (SHD) was around $70 \%$ of that of the fullystrengthened specimens. With the same material properties and test loading, tensile cracked specimens $\left(\beta=90^{\circ}\right)$ partially strengthened using the single-sided method showed improvement in the fatigue life of $44 \%$, and $33 \%$ that of the double-sided strengthening method for damage levels of $10 \%$, and $30 \%$ respectively. It is obvious that applying the composite patch only on one side of the cracked components shows less fatigue improvement for longer initial crack length.

2. Tensile mode-I controlled the behaviour of test specimens with loading angles larger than $60^{\circ}$ for different initial damage levels, whereas the combined action of tensile and shear stresses (I+II) was obvious for loading angles between $60^{\circ}-10^{\circ}$.

3. The concept of shifting in mixed-mode crack growth curve proposed in the earlier study of the authors [34] for CFRP-strengthened steel plates with small damage is obvious for higher levels of damage. In this paper, the understanding of the shifting concept of mixed-mode crack propagation curves is extended to a wider range of damage levels, i.e. the higher the degree of damage, the less the shift in the crack growth curves.

4. Based on the shifting concept, the mixed-mode (I+II) crack propagation curve can be approximated by the mode I crack growth curve using a modifying factor. The test results were employed to derive mixed-mode modification factors for different loading angles and damage levels. With the mixed-mode modification factor, the fatigue life of CFRPstrengthened plates can be predicted from the same crack growth curve of mode I. 
5. A higher percentage increase in fatigue life was found when the strengthening was applied to specimens with greater damage levels. This is probably due to the low fatigue life of reference specimens without CFRP. The fatigue performance of the CFRP-strengthened specimens with different crack angles highlights the importance of the earlier repair of the notched plates.

\section{ACKNOWLEDGMENTS}

The authors gratefully acknowledge the financial support provided by the Australian Research Council through an ARC Linkage Grant (LP140100543) with VicRoads and S\&P Clever Reinforcement Company AG as industry partners. The first author wishes to thank the Higher Committee for Education Development in Iraq for sponsoring his research at Monash University. Thanks are given to all technical staff in the civil engineering laboratory at Monash University, especially Mr. Long Goh and Mr. Saravan Mani, for their technical support.

\section{REFERENCES}

1. Zerbst, U., \& Ainsworth, R.A. An overview of failure assessment methods in codes and standards. A.R. Ainsworth, K.-H. Schwalbe (Eds.), Comprehensive structural integrity practical failure assessment methods, vol. 7, Elsevier, Oxford (2003), pp. 1-482.

2. Hollaway, L.C. and J. Cadei, Progress in the technique of upgrading metallic structures with advanced polymer composites. Progress in Structural Engineering and Materials, 2002; 4(2): p. 131-148.

3. Zhao, X.-L. and L. Zhang, State-of-the-art review on FRP strengthened steel structures. Engineering Structures, 2007; 29(8): p. 1808-1823.

4. Dawood, M., Fiber-reinforced polymer (FRP) composites for strengthening steel structures, Chapter 15. In Uddin N, Editor. Developments in Fiber-Reinforced Polymer (FRP) 
Composites for Civil Engineering. Cambridge, England.Woodhead Publishing. 2013; p. 382409.

5. Hollaway, L.C., The evolution of and the way forward for advanced polymer composites in the civil infrastructure. Construction and Building Materials, 2003; 17(6-7): p. 365-378.

6. Zhao, X.-L., FRP Strengthened Metallic Structures. 2013, Boca Raton, FL.: CRC Press, Taylor \& Francis Group.

7. Zerbo, A., Di Tommaso, and L. Ceriolo. FRP strengthening systems for metallic structures: a state of the aret. In Structural Analysis of Historical Constructions-2 Volume Set: Possibilities of Numerical and Experimental Techniques-Proceedings of the IVth Int. Seminar on Structural Analysis of Historical Constructions, 10-13 November Padova, Italy. CRC Press. 2004.

8. Ghafoori, E., A. Schumacher, and M. Motavalli, Fatiguebehaviourof notched steel beams reinforced with bonded CFRP plates: Determination of prestressing level for crack arrest. Engineering Structures, 2012; 45: p. 270-283.

9. Ghafoori, E., M. Motavalli, J. Botsis, A. Herwig, and M. Galli, Fatigue strengthening of damaged metallic beams using prestressed unbonded and bonded CFRP plates. International Journal of Fatigue, 2012; 44: p. 303-315.

10. Ghafoori, E., M. Motavalli, A. Nussbaumer, A. Herwig, G.S. Prinz, and M. Fontana, Design criterion for fatigue strengthening of riveted beams in a 120-year-old railway metallic bridge using pre-stressed CFRP plates. Composites Part B: Engineering, 2015; 68: p. 1-13.

11. Ghafoori, E., M. Motavalli, A. Nussbaumer, A. Herwig, G.S. Prinz, and M. Fontana, Determination of minimum CFRP pre-stress levels for fatigue crack prevention in retrofitted metallic beams. Engineering Structures, 2015; 84: p. 29-41. 
12. Ghafoori, E. and M. Motavalli, Flexural and interfacialbehaviourof metallic beams strengthened by prestressed bonded plates. Composite Structures, 2013; 101: p. 22-34.

13. Ghafoori, E. and M. Motavalli, a retrofit theory to prevent fatigue crack initiation in aging riveted bridges using Carbon Fiber-Reinforced Polymer materials. Polymers, 2016; 8(8): p. 308.

14. Ghafoori, E. and M. Motavalli, Lateral-torsional buckling of steel I-beams retrofitted by bonded and un-bonded CFRP laminates with different pre-stress levels: Experimental and numerical study. Construction and Building Materials, 2015; 76: p. 194-206.

15. Bassetti, A., Nussbaumer, A. and Hirt, A. In:, Fatigue life extension of riveted bridge members using prestressed carbon fibre composites, in International Conference on Steel Structures of the 2000's ECCS. 2000. p. 375-380.

16. Colombi, P., A. Bassetti, and A. Nussbaumer, Analysis of cracked steel members reinforced by pre-stress composite patch. Fatigue \& Fracture of Engineering Materials \& Structures, 2003; 26(1): p. 59-66.

17. Liu, H., R. Al-Mahaidi, and X.L. Zhao, Experimental study offatigue crack growth behaviour in adhesively reinforced steel structures. Composite Structures, 2009; 90(1): p. 12-20.

18. Sean C. Jones and Scott A. Civjan, Application of fiber reinforced polymer overlays to extend steel fatigue life. Journal of Composites for Construction, 2003; 7(4): p. 331-338.

19. Wu, C., X.-L. Zhao, R. Al-Mahaidi, M. Emdad, and W. Duan, Fatigue tests of cracked steel plates strengthened with UHM CFRP plates. Advances in Structural Engineering, 2012; 15(10): p. 1801-1816.

20. Hosseini-Toudeshky, H., G. Sadeghi, and H.R. Daghyani, Experimental fatigue crack growth and crack-front shape analysis of asymmetric repaired aluminium panels with glass/epoxy composite patches. Composite Structures, 2005; 71(3-4): p. 401-406. 
21. Tsouvalis, N.G., L.S. Mirisiotis, and D.N. Dimou, Experimental and numerical study of the fatigue behaviour of composite patch reinforced cracked steel plates. International Journal of Fatigue, 2009; 31(10): p. 1613-1627.

22. Wu, C., X.L. Zhao, R. Al-Mahaidi, M.R. Emdad, and W.H. Duan, Fatigue tests on steel plates with longitudinal weld attachment strengthened by ultra high modulus carbon fibre reinforced polymer plate. Fatigue \& Fracture of Engineering Materials \& Structures, 2013; 36(10): p. 1027-1038.

23. Aljabar, N.J., Zhao X. L., Al-Mahaidi R. , Ghafoori E., Motavalli M. , and Powers N., Experimental investigation on CFRP Strengthened steel plates with inclined cracks, in 8th International Conference on Bridge Maintenance, Safety and Management. 2016, In Preparation: Foz do Iguaçu, Brazil.

24. Yu, Q.Q., T. Chen, X.L. Gu, X.L. Zhao, and Z.G. Xiao, Fatigue behaviour of CFRP strengthened steel plates with different degrees of damage. Thin-Walled Structures, 2013; 69: p. 10-17.

25. Yu, Q.-Q., X.-L. Zhao, R. Al-Mahaidi, Z.-G. Xiao, T. Chen, and X.-L. Gu, Tests on cracked steel plates with different damage levels strengthened by CFRP laminates. International Journal of Structural Stability and Dynamics, 2014; 14(06): p. 1450018.

26. Yu, Q.Q., X.L. Zhao, T. Chen, X.L. Gu, and Z.G. Xiao, Crack propagation prediction of CFRP retrofitted steel plates with different degrees of damage using BEM. Thin-Walled Structures, 2014; 82: p. 145-158.

27. Wang, H.-T., G. Wu, and Z.-S. Wu, Effect of FRP configurations on the fatigue repair effectiveness of cracked steel plates. Journal of Composites for Construction, 2013; 18(1): p. 04013023. 
28. Colombi, P., G. Fava, and L. Sonzogni, Effect of initial damage level and patch configuration on the fatigue behaviour of reinforced steel plates. Fatigue \& Fracture of Engineering Materials \& Structures, 2015; 38(3): p. 368-378.

29. Qian, J. and A. Fatemi, Mixed mode fatigue crack growth: A literature survey. Engineering Fracture Mechanics, 1996; 55(6): p. 969-990.

30. Karbhari, V.M., J.W. Chin, D. Hunston, B. Benmokrane, T. Juska, R. Morgan, J.J. Lesko, U. Sorathia, and D. Reynaud, Durability gap analysis for Fiber-Reinforced Polymer composites in civil infrastructure. Journal of Composites for Construction, 2003; 7(3): p. 238-247.

31. Kamruzzaman, M., M.Z. Jumaat, N.H. Sulong, and A.B. Islam, A review on strengthening steel beams using FRP under fatigue. The Scientific World Journal, 2014; p. 1-21.

32. Shaat, A., D. Schnerch, A. Fam, and S. Rizkalla, Retrofit of steel structures using fiberreinforced polymers (FRP): State-of-the-art, in Transportation Research Board (TRB) Annual Meeting. Washington, DC, USA, 2004. CD-ROM (04-4063).

33. Teng, J.G., Yu, T., Fernando, D., Strengthening of steel structures with fiber-reinforced polymer composites. Journal of Constructional Steel Research, 2012; 78: p. 131-143.

34. Aljabar, N.J., X.L. Zhao, R. Al-Mahaidi, E. Ghafoori, M. Motavalli, and N. Powers, Effect of crack orientation on fatiguebehaviourof CFRP-strengthened steel plates. Composite Structures, 2016; 152: p. 295-305.

35. AS-1391, Methods of Tensile Testing of Metals. Standards Australia: Sydney, Australia, 1991.

36. Fawzia, S., Bond Characteristics between Steel and Carbon Fibre Reinforced Polymer (CFRP) Composites, PhD Thesis. 2007, Monash University: Melbourne, Australia.

37. Teng, J., D. Fernando, T. Yu, and X. Zhao, Treatment of steel surfaces for effective adhesive bonding, in Advances in FRP Composites in Civil Engineering. Springer. 2011; p. 865-868. 
38. Zhao, X.-L., T. Wilkinson, and G. Hancock, Cold-formed tubular members and connections, Elsevier: Oxford, 2005, p. 179-206.

39. Hua, G., Brown M. W. and Miller, K. J. , Mixed-mode fatigue thresholds. Fatigue \& Fracture of Engineering Materials \& Structures, 1982; 5: p. 1-17.

40. Anderson, T.L., Fracture mechanics - Fundamentals and applications., 3rd ed. Boca Raton, FL, USA: CRC Press, Taylor \& Francis Group:2005. 


\section{FIGURES}

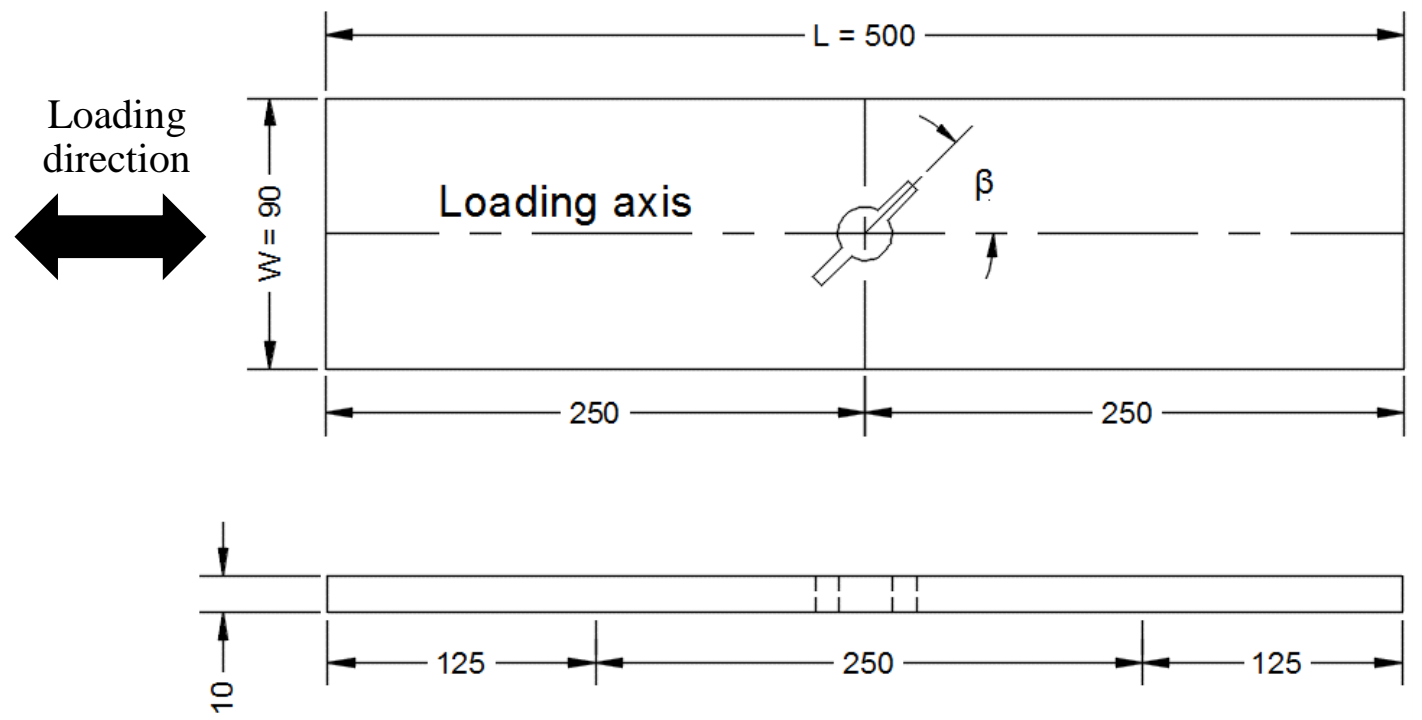

(a)

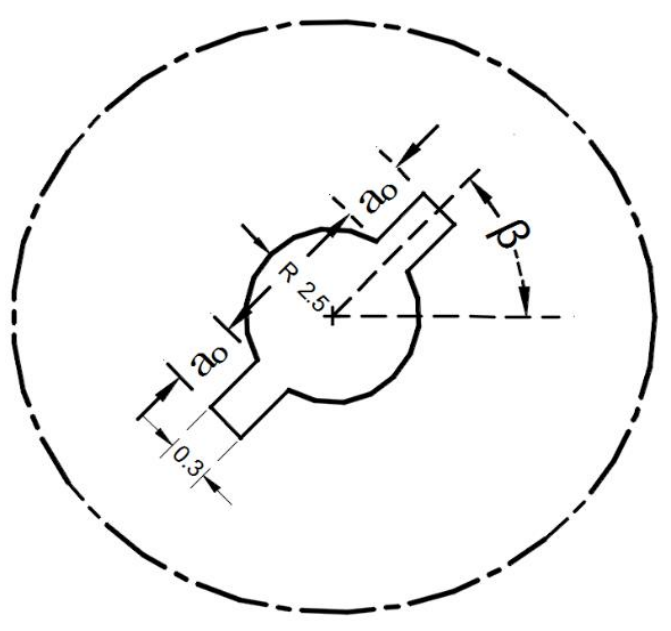

(b)

Figure 1. Specimen details: (a) geometry and dimensions, (b) notch details, (in mm, not to scale) 


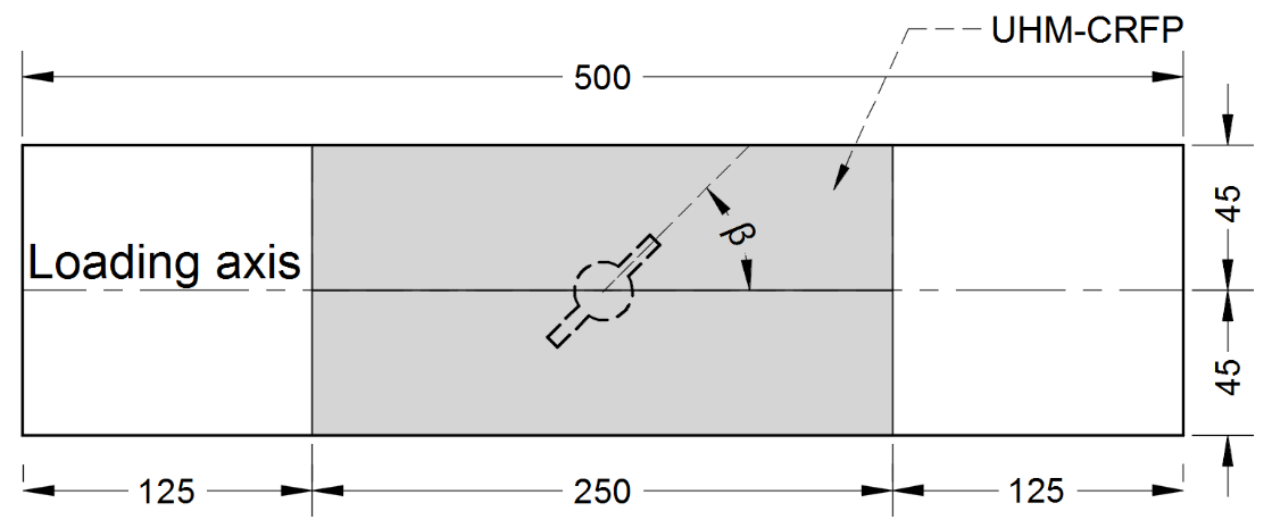

(a)

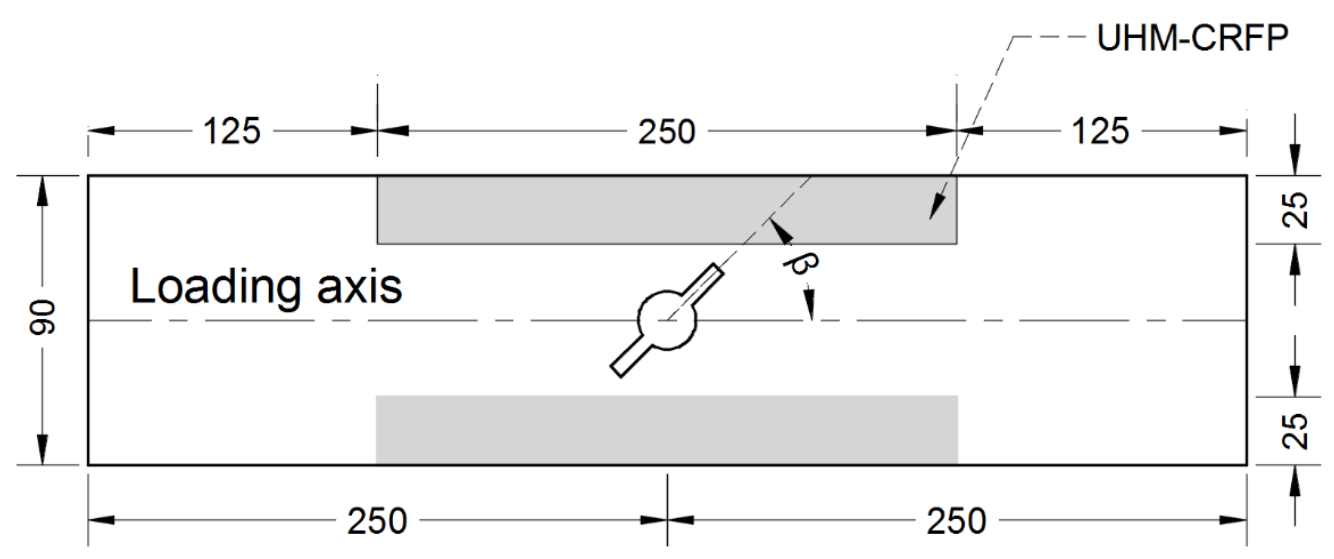

(b)

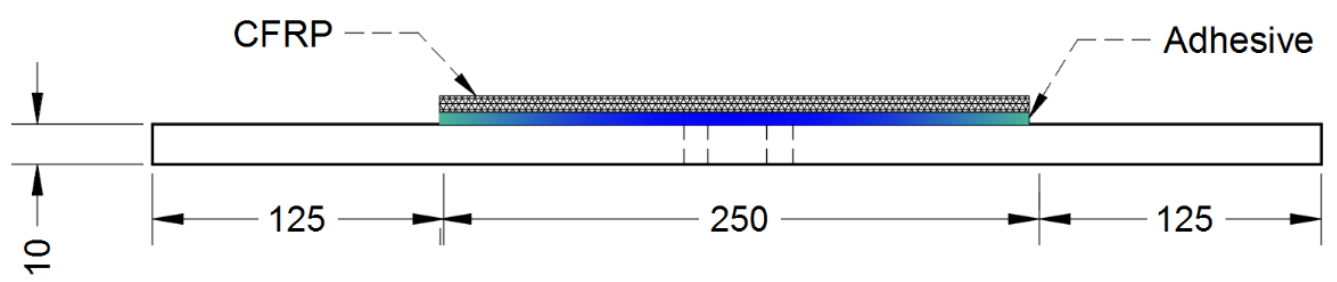

(c)

Figure 2. CFRP configurations of the strengthened steel plates: (a) fully-strengthened specimen (SHA), (b) partially-strengthened specimen, (SHD), (in mm, not to scale) 


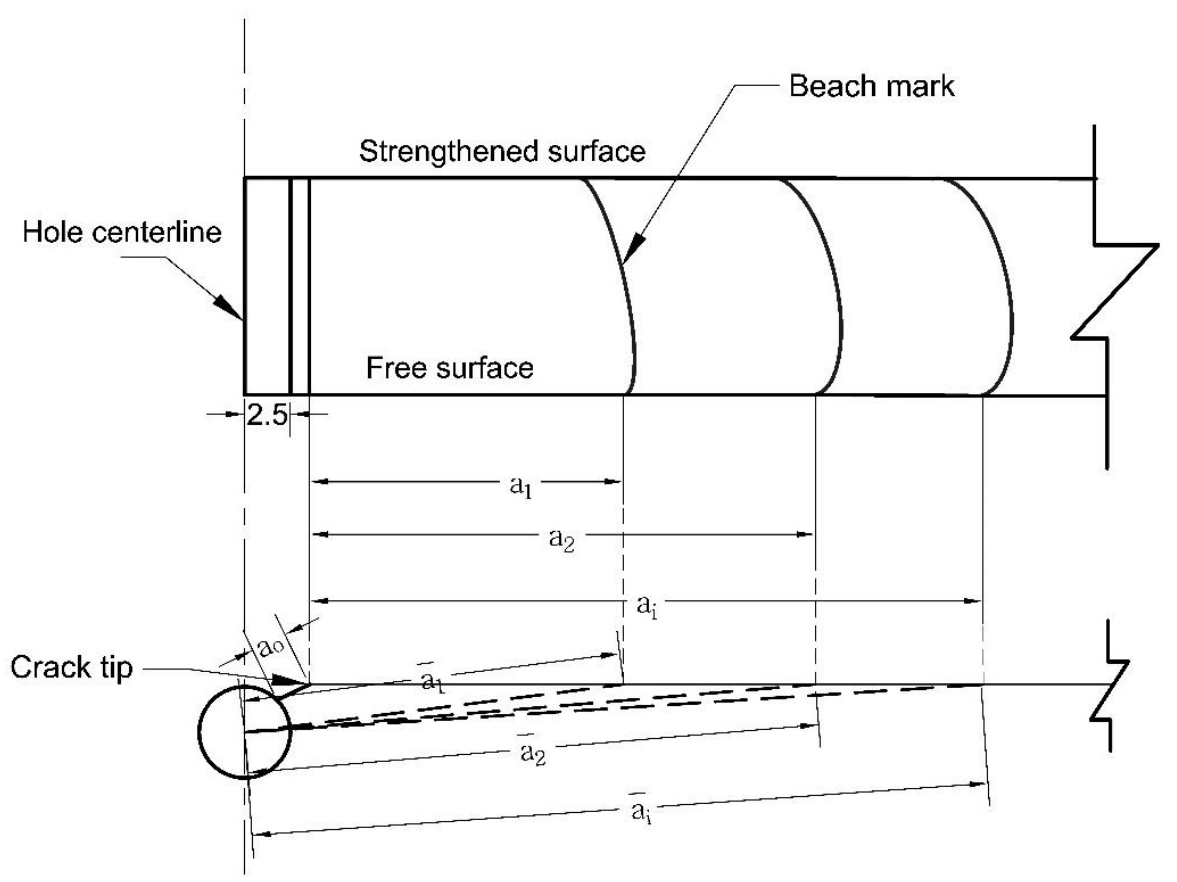

Figure 3. Schematic view of the measurement of the crack length: (a) cross section of the fracture surface, with measured crack length $\left(a_{1}, a_{2}\right.$, and $\left.a_{3}\right)$, and (b) the calculated crack length, $\overline{a_{1}}, \overline{a_{2}}$, and $\overline{a_{l}}$ ) 


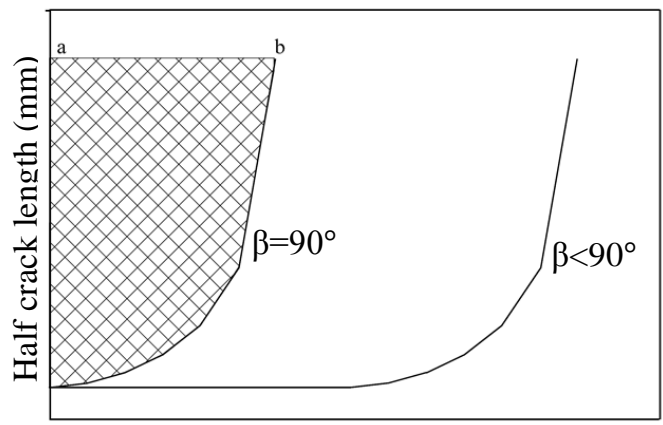

Number of cycles

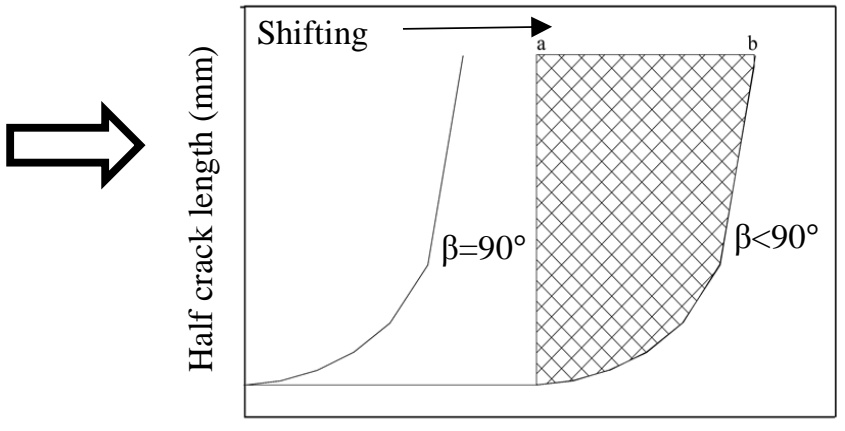

Number of cycles

Figure 4. Schematic view of the shifting phenomenon in mixed mode fatigue crack growth curves "identified in Ref. [34]" 


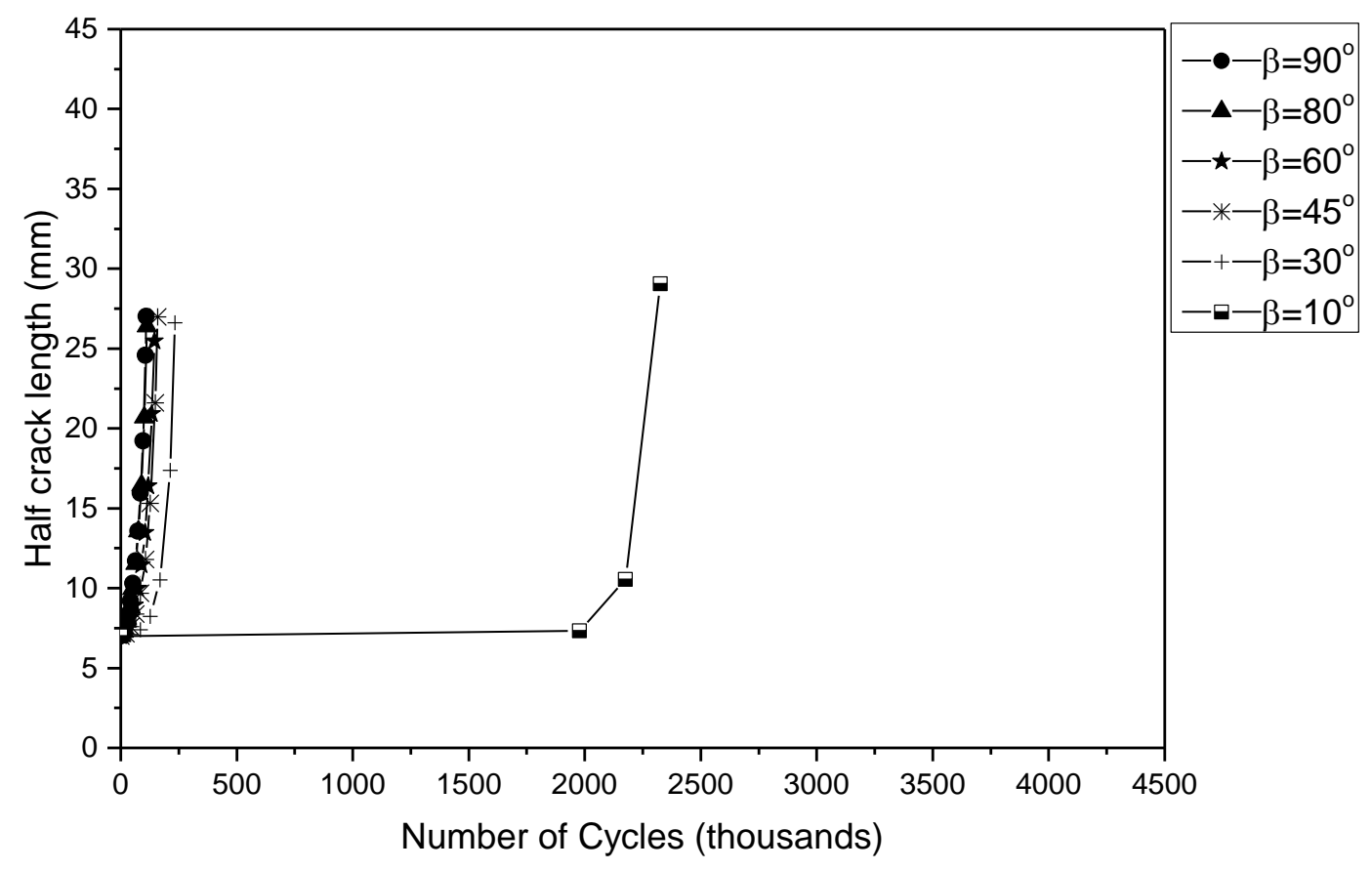

Figure 5. Crack length vs. number of cycles for steel plates without CFRP with damage level of $10 \%$ 


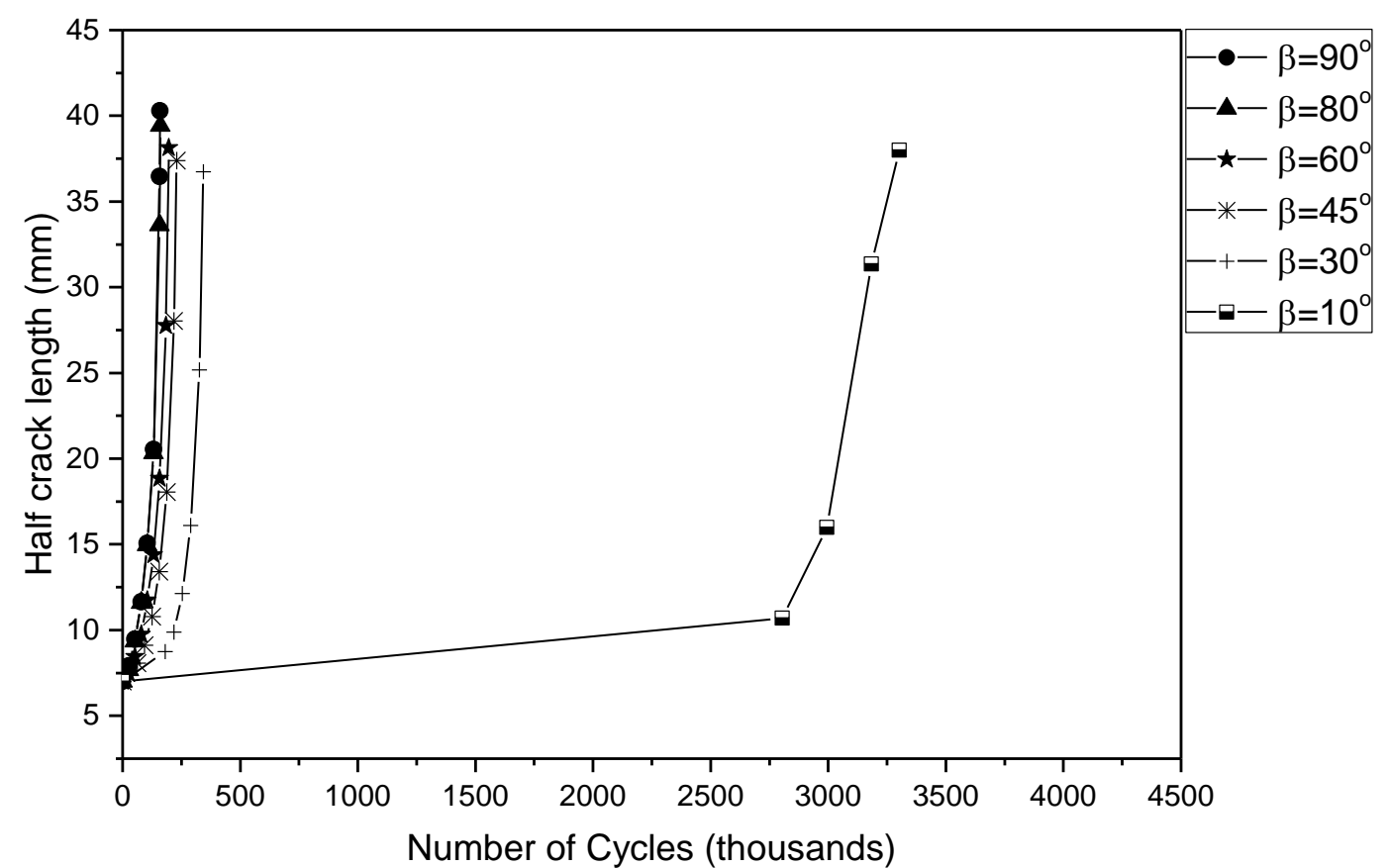

Figure 6. Crack length vs. number of cycles for partially-strengthened plates with damage level of $10 \%$ 


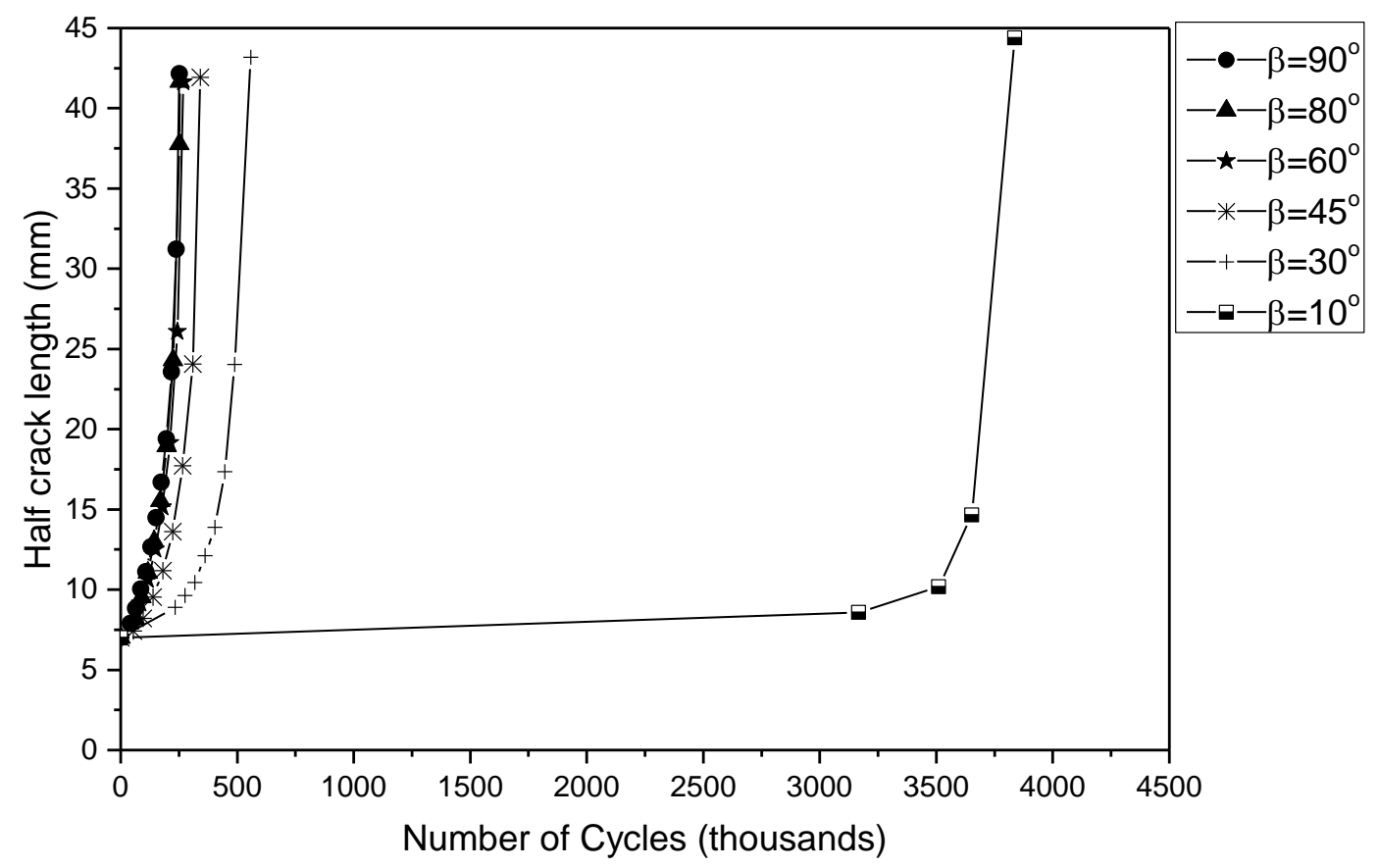

Figure 7. Crack length vs. number of cycles for fully-strengthened plates with damage level of $10 \%$. 


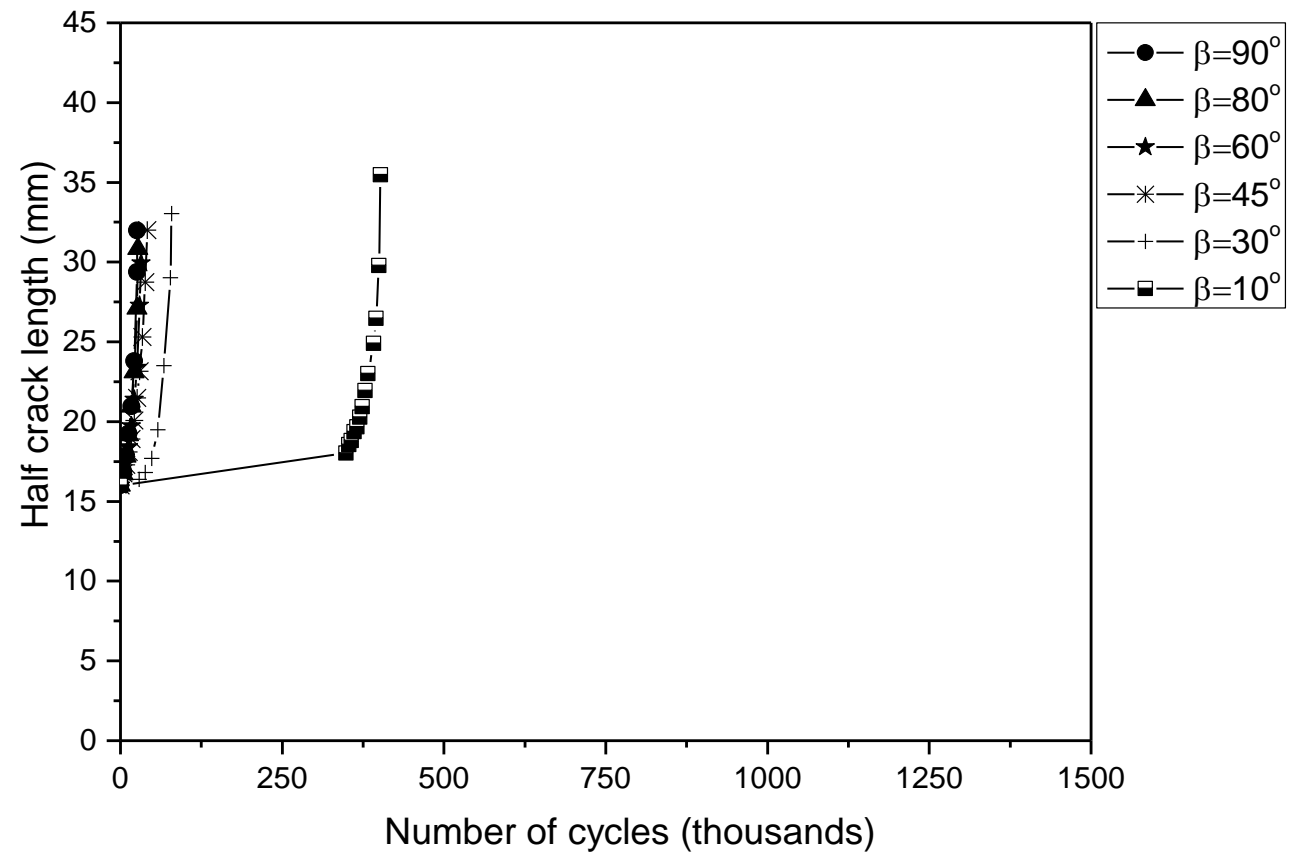

Figure 8. Crack length vs. number of cycles for steel plates without CFRP with damage level of $30 \%$ 


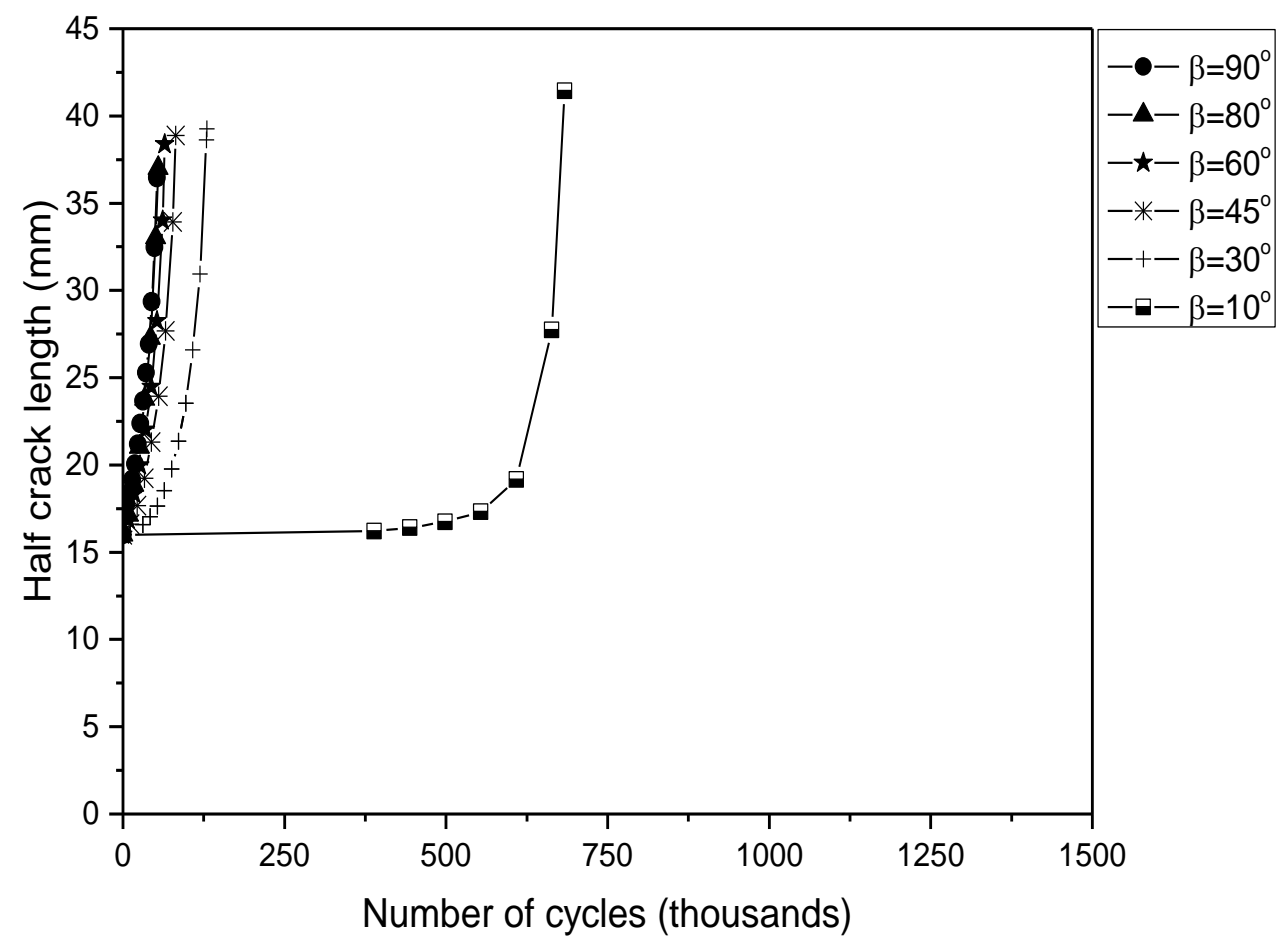

Figure 9. Crack length vs. number of cycles for partially-strengthened plates with damage level of $30 \%$ 


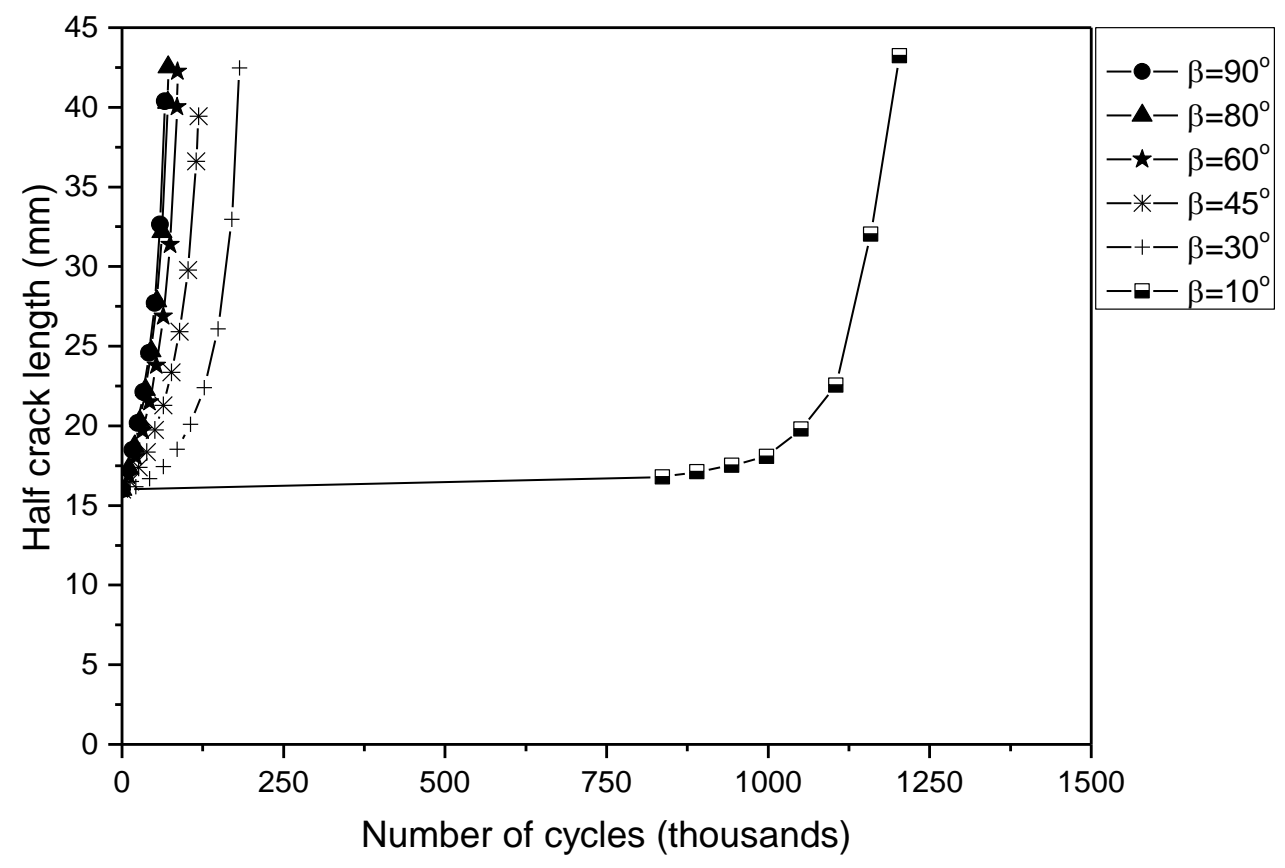

Figure 10. Crack length vs. number of cycles for fully-strengthened plates with damage level of $30 \%$. 


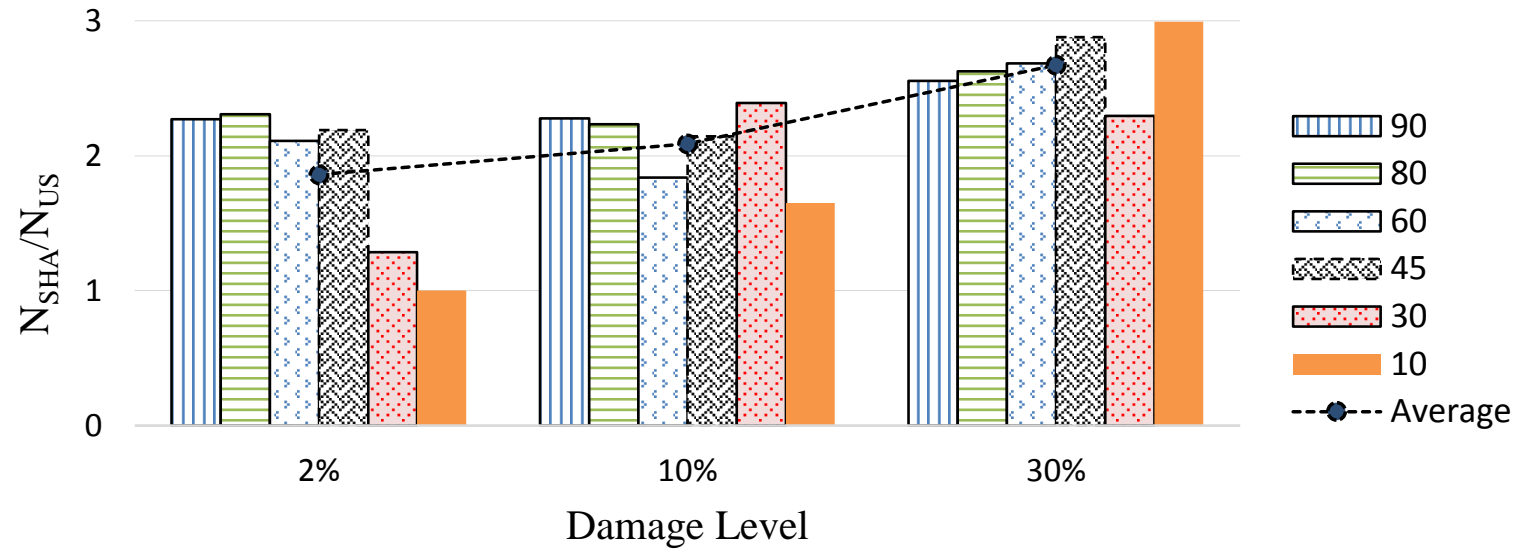

Figure 11. Fatigue propagation life improvement versus damage degree for fully-strengthened plates 
3

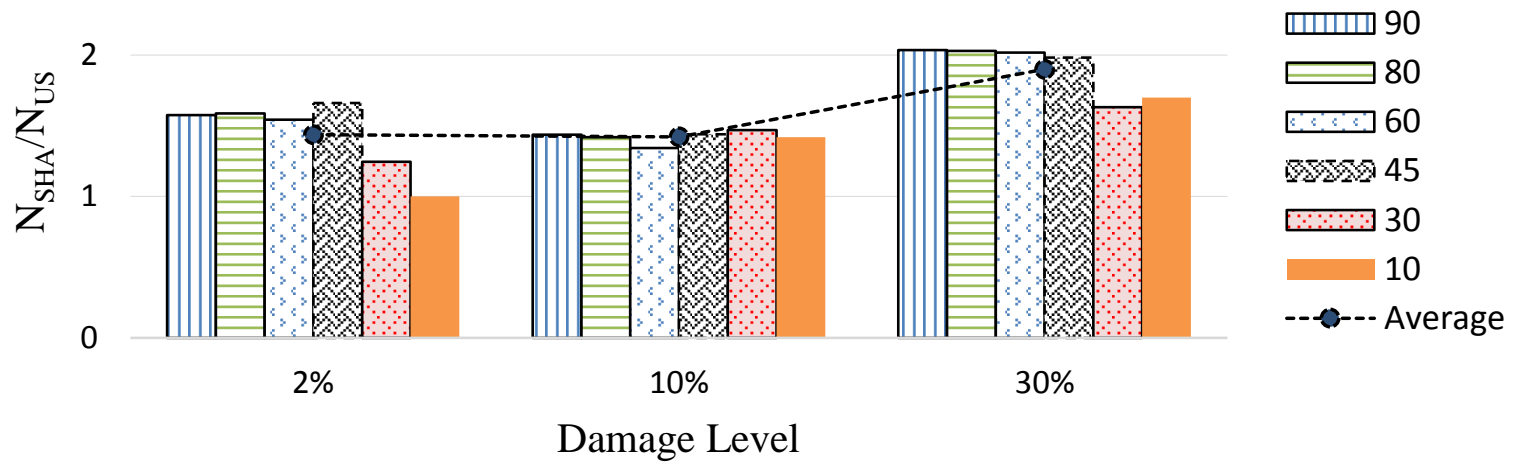

Figure 12. Fatigue propagation life improvement versus damage degree for partiallystrengthened plates 


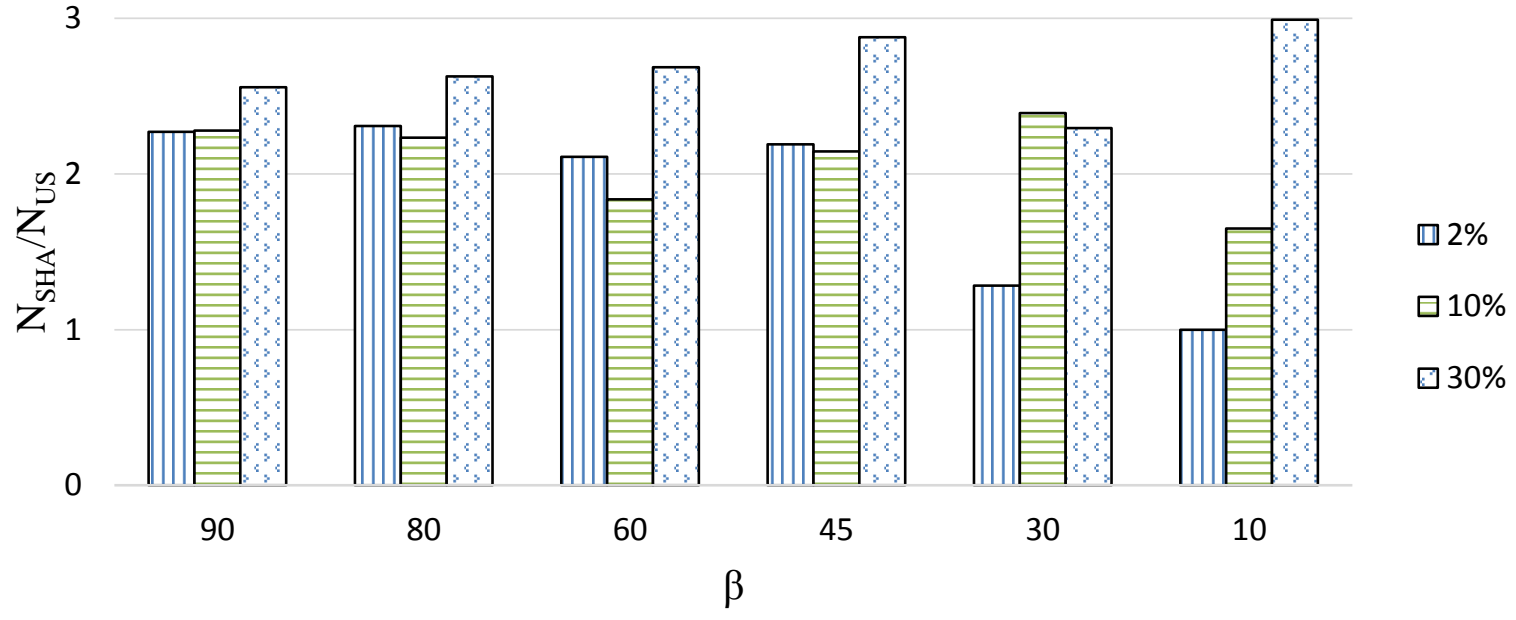

Figure 13. Fatigue propagation life improvement versus loading angle for fully-strengthened plates 
3

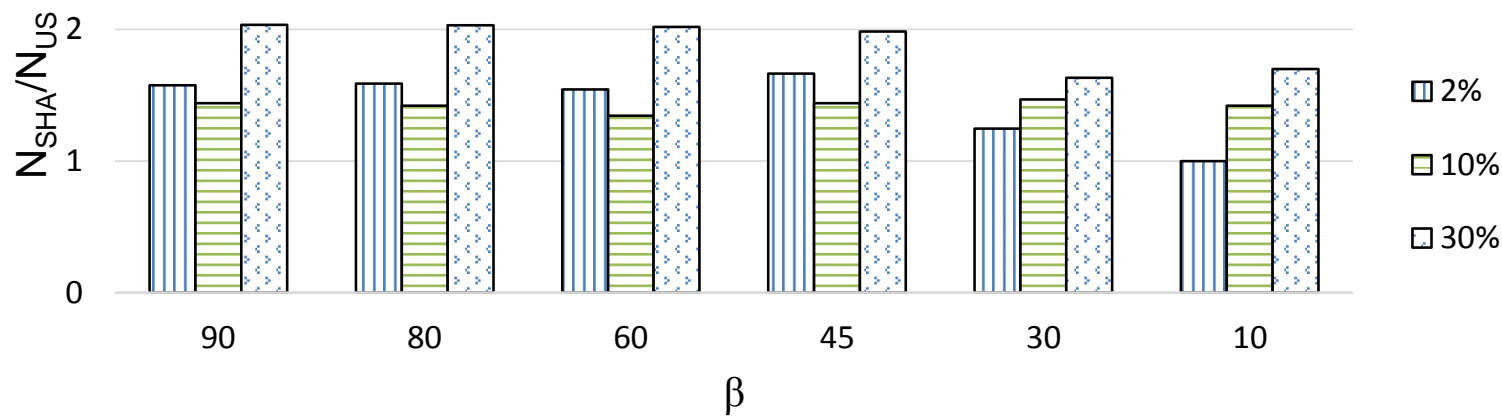

Figure 14. Fatigue propagation life improvement versus loading angle for partiallystrengthened plates 


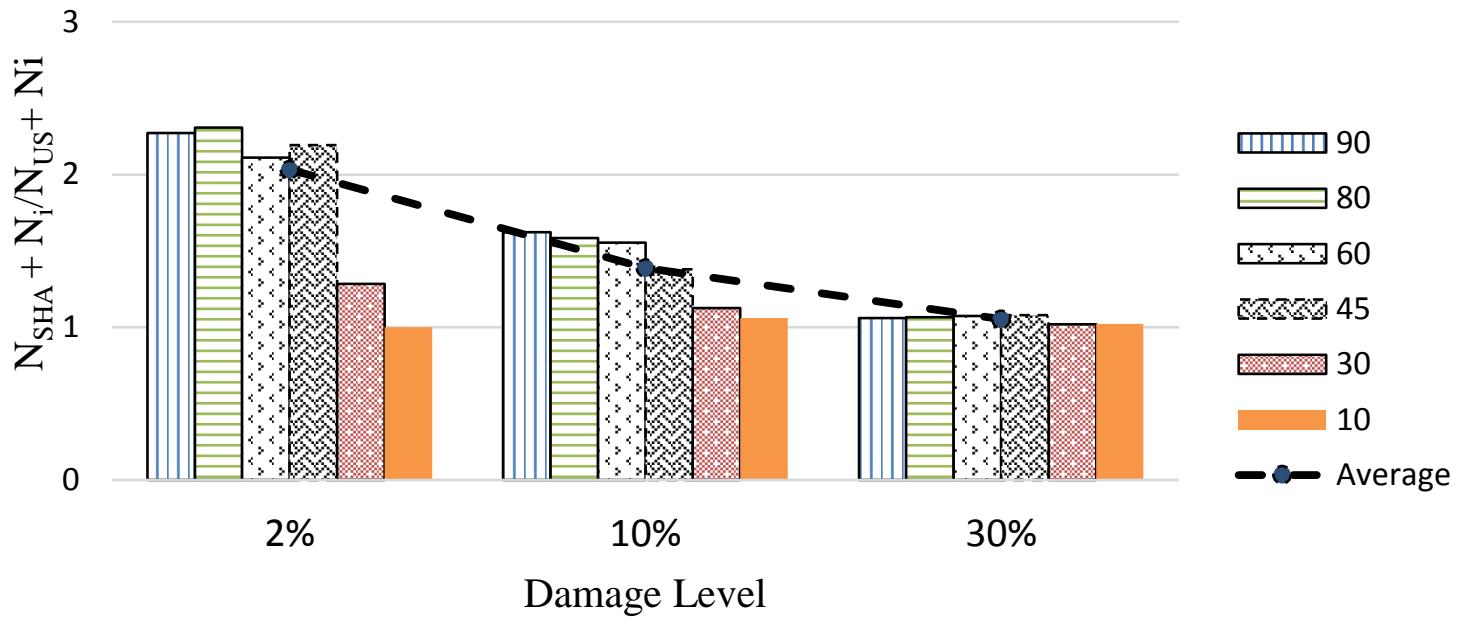

Figure 15. Total tensile fatigue life improvement versus damage degree of fully-strengthened plates 


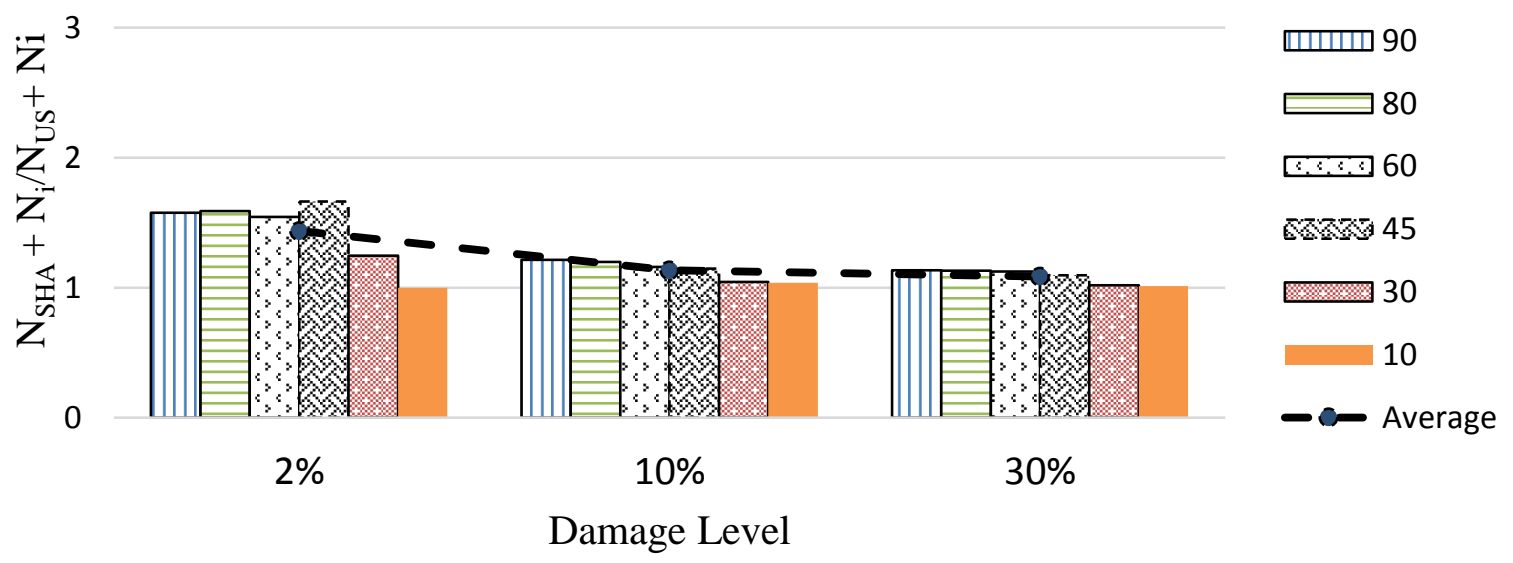

Figure 16. Total tensile fatigue life improvement versus damage degree of partiallystrengthened plates 


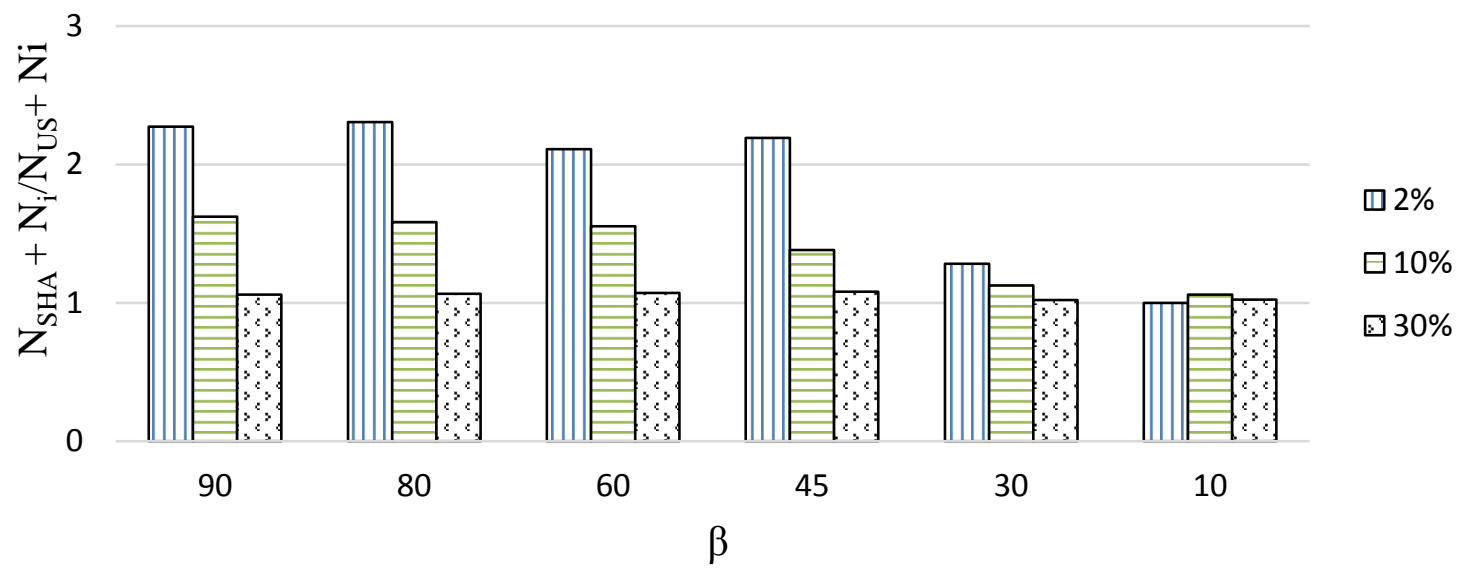

Figure 17. Total tensile fatigue life improvement versus loading angle of fully-strengthened plates 


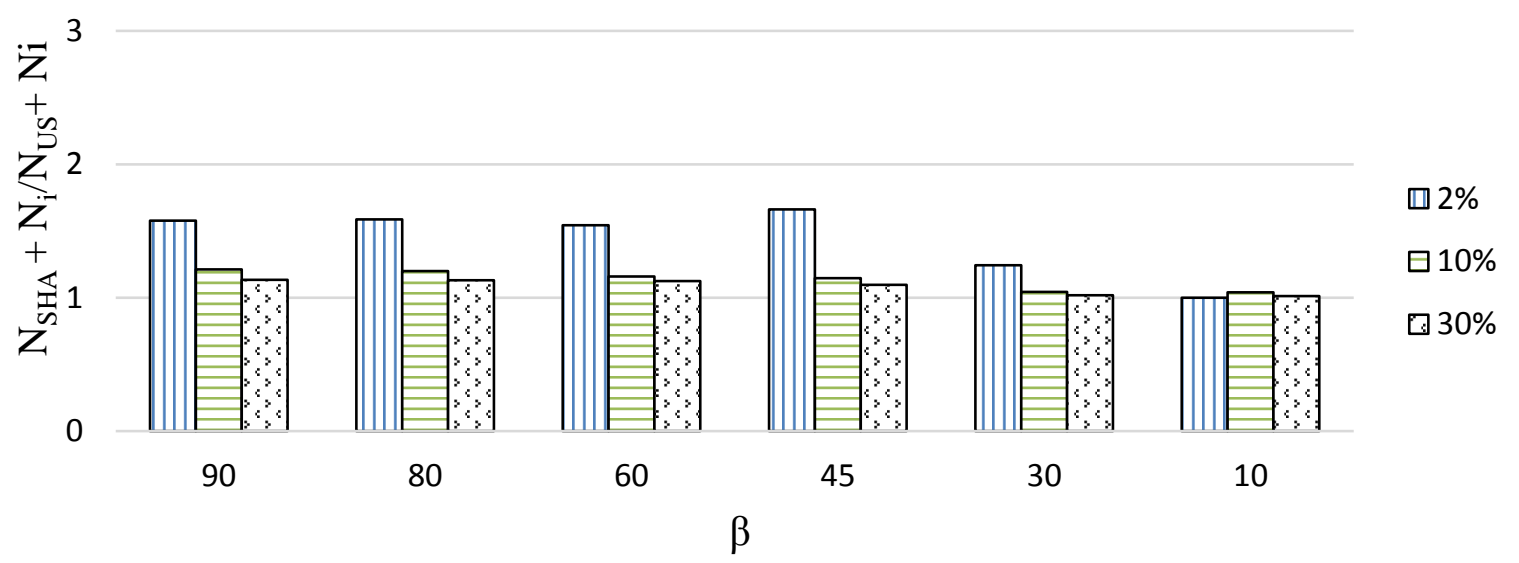

Figure 18. Total tensile fatigue life improvement versus loading angle of partially-strengthened plates 


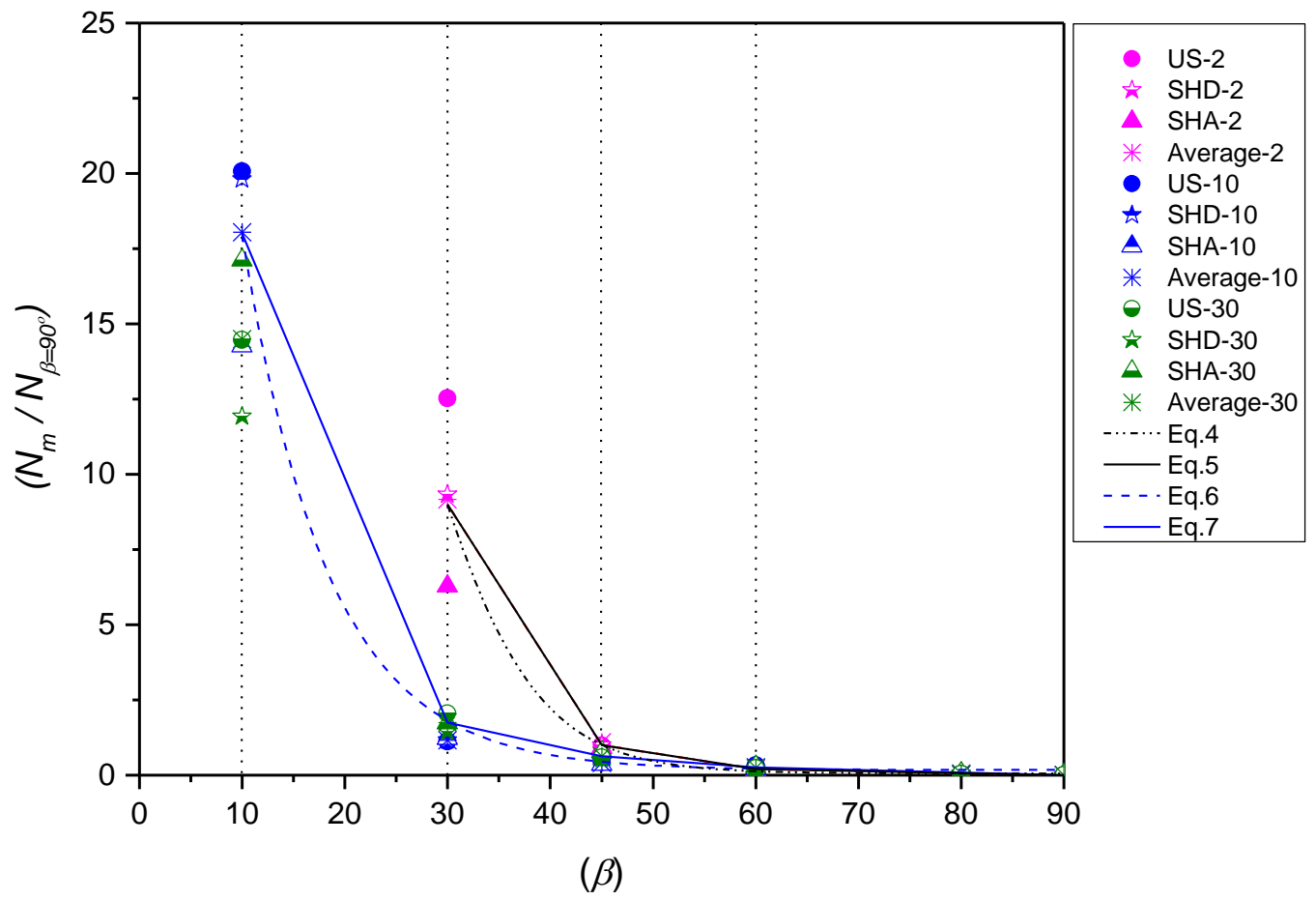

Figure 19. Experimental values of the mixed mode modification factor 


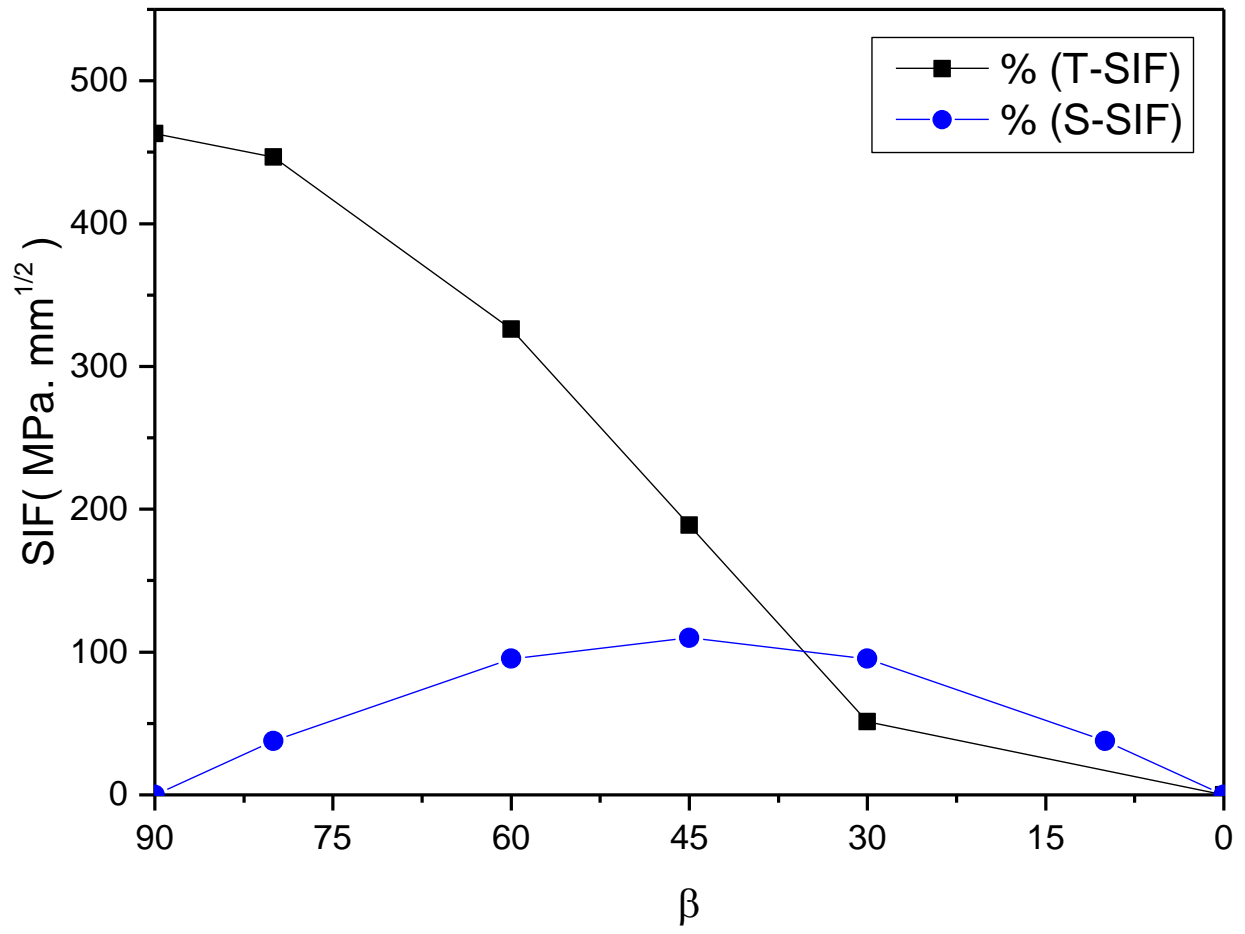

Figure 20. Proportional change in stress intensity factors for different crack orientation for specimens US-2\%. 


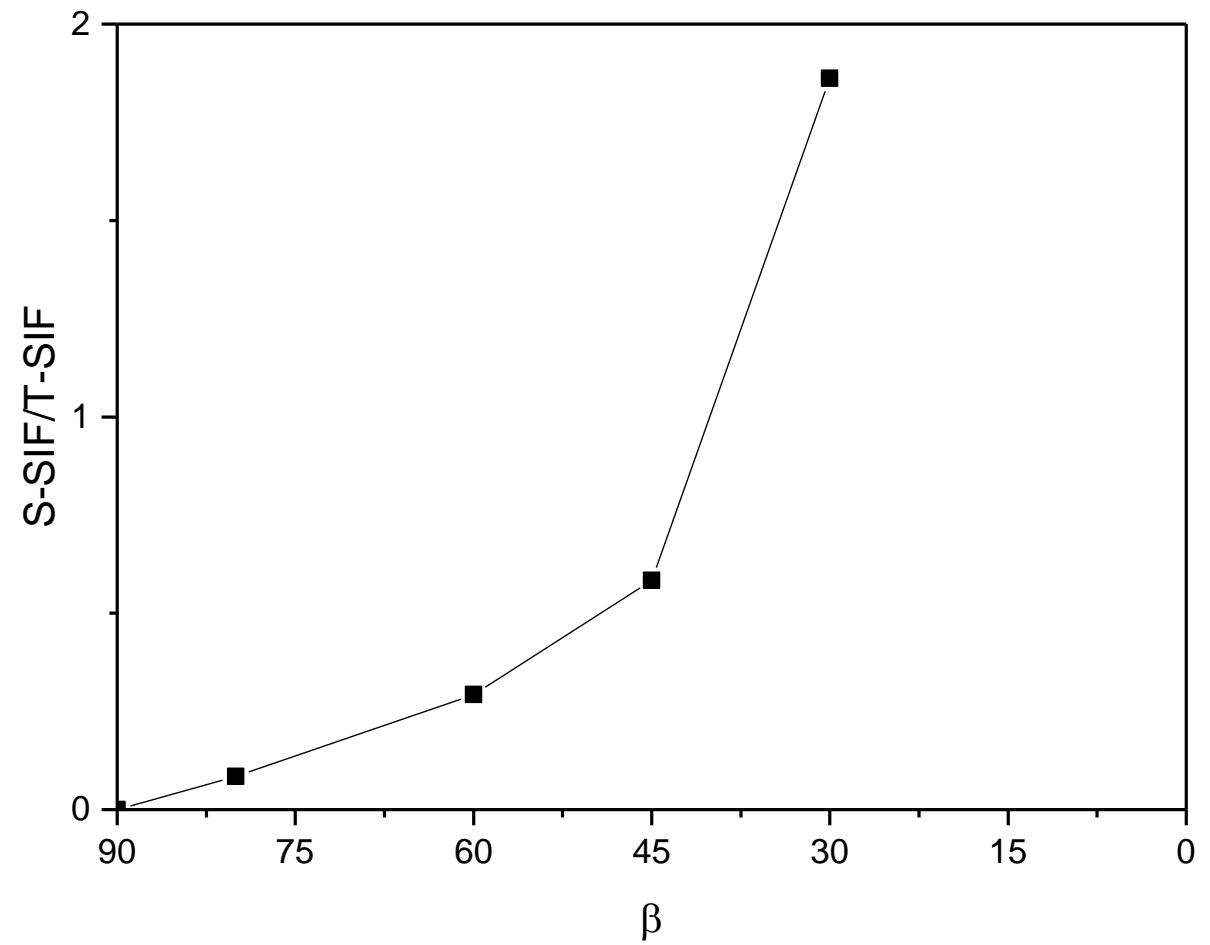

Figure 21. The mode-mixity for different crack orientation for specimens US-2\%. 


\section{TABLES}

Table 1. Material properties of the test specimens

\begin{tabular}{llll}
\hline Material & Steel & CFRP Laminates [19] & $\begin{array}{c}\text { Araldite 420 } \\
{[36]}\end{array}$ \\
\hline Tensile strength (MPa) & 500 & 1603 & 28.6 \\
Yield strength (MPa) & 329 & - & - \\
Young's modulus (GPa) & 204 & 478 & 1.9 \\
Thickness (mm) & 10 & 1.46 & \\
\hline
\end{tabular}


Table 2.Summary of the test results of $2 \%$ damage level from Ref. [34].

\begin{tabular}{|c|c|c|c|c|c|}
\hline $\begin{array}{l}\text { Specimen } \\
\text { Symbol }\end{array}$ & $\begin{array}{c}\text { Fatigue loading } \\
\text { level }\end{array}$ & Fatigue life & $\begin{array}{l}\text { Fatigue life } \\
\text { Improvement } \\
\text { factor }\end{array}$ & $\begin{array}{c}\text { Equivalent } \\
\text { fatigue life of test } \\
\text { loading }\end{array}$ & $\mathrm{Nm}$ \\
\hline US-2-90 & \multirow{5}{*}{$0.46 \mathrm{fy}$} & 202,784 & - & 202,784 & 0 \\
\hline US-2-80 & & 210,860 & - & 210,860 & 8,076 \\
\hline US-2-60 & & 251,221 & - & 251,221 & 48,437 \\
\hline US-2-45 & & 402,436 & - & 402,436 & 199,652 \\
\hline US-2-30 & & $>10^{7}$ & - & $\mathrm{N} / \mathrm{A}$ & N/A \\
\hline US-2-10 & \multirow{4}{*}{$0.6 \mathrm{fy}$} & $>10^{7}$ & - & N/A & $\mathrm{N} / \mathrm{A}$ \\
\hline US-2-30 & & $1,139,899$ & - & $2,612,914$ & $2,410,130$ \\
\hline US-2-30 & & $1,253,736$ & - & $2,873,855$ & $2,671,071$ \\
\hline US-2-10 & & $>10^{7}$ & - & & \\
\hline SHD-2-90 & \multirow{4}{*}{0.46 fy } & 319,724 & 1.6 & 319,724 & 0 \\
\hline SHD-2- $80^{\circ}$ & & 334,738 & 1.6 & 334,738 & 15,014 \\
\hline SHD-2- $60^{\circ}$ & & 388,030 & 1.5 & 388,030 & 68,306 \\
\hline SHD-2-45 & & 669,035 & 1.7 & 669,035 & 349,310 \\
\hline SHD-2-30 & \multirow{2}{*}{0.6 fy } & $1,418,742$ & 1.2 & $3,252,087$ & $2,932,363$ \\
\hline SHD-2-10 & & $>10^{7}$ & Run Out & N/A & $\mathrm{N} / \mathrm{A}$ \\
\hline SHA-2-90 & \multirow{4}{*}{0.46 fy } & 460,684 & 2.3 & 460,684 & 0 \\
\hline SHA-2-80 & & 486,592 & 2.3 & 486,592 & 25,908 \\
\hline SHA-2- $60^{\circ}$ & & 529,940 & 2.1 & 529,940 & 69,256 \\
\hline SHA-2- $45^{\circ}$ & & 881,792 & 2.2 & 881,792 & 421,108 \\
\hline SHA-2-30 & \multirow{2}{*}{0.6 fy } & $1,463,308$ & 1.3 & $3,354,242$ & $2,893,558$ \\
\hline SHA-2-10 & & $>10^{7}$ & Run Out & N/A & N/A \\
\hline
\end{tabular}


Table 3. Experimental program and test results of specimens with $10 \%$ damage level

\begin{tabular}{|c|c|c|c|c|c|c|c|}
\hline $\begin{array}{l}\text { Specimen } \\
\text { symbol }\end{array}$ & $\begin{array}{c}\text { Fatigue } \\
\text { loading } \\
\text { level }\end{array}$ & $\begin{array}{c}\text { Pmax } \\
(\mathrm{kN})\end{array}$ & $\begin{array}{l}\text { Pmin } \\
(\mathrm{kN})\end{array}$ & $\begin{array}{l}\text { Fatigue } \\
\text { life } \\
\text { (cycles) }\end{array}$ & $\begin{array}{l}\text { Fatigue life } \\
\text { Improvement } \\
\text { factor }\end{array}$ & $\begin{array}{c}\text { Equivalent } \\
\text { fatigue life of } \\
\text { test loading }\end{array}$ & $\mathrm{Nm}$ \\
\hline US-10-90 ${ }^{\circ}$ & \multirow{5}{*}{0.46 fy } & \multirow{5}{*}{135} & \multirow{5}{*}{13.5} & 110,413 & N/A & 110,413 & 0 \\
\hline US-10-80 $80^{\circ}$ & & & & 113,579 & N/A & 113,579 & 3,166 \\
\hline US-10-60 & & & & 146,041 & N/A & 146,041 & 35,628 \\
\hline US-10-45 ${ }^{\circ}$ & & & & 159,370 & N/A & 159,370 & 48,957 \\
\hline US-10-30 & & & & 233,599 & N/A & 233,599 & 123,186 \\
\hline US-10-10 & $0.6 \mathrm{fy}$ & 178 & 17.8 & $1,014,570$ & N/A & $2,325,631$ & $2,215,218$ \\
\hline SHD- $90^{\circ}$ & \multirow{5}{*}{0.46 fy } & \multirow{5}{*}{135} & \multirow{5}{*}{13.5} & 158,726 & 1.44 & 158,726 & 0 \\
\hline SHD- $80^{\circ}$ & & & & 161,171 & 1.42 & 161,171 & 2,445 \\
\hline SHD- $60^{\circ}$ & & & & 196,245 & 1.34 & 196,245 & 37,519 \\
\hline SHD- $45^{\circ}$ & & & & 229,414 & 1.44 & 229,414 & 70,688 \\
\hline SHD-30 & & & & 343,015 & 1.47 & 343,015 & 184,289 \\
\hline SHD-10 & $0.6 \mathrm{fy}$ & 178 & 17.8 & $1,440,748$ & 1.42 & $3,302,530$ & $3,143,804$ \\
\hline SHA- $90^{\circ}$ & \multirow{5}{*}{0.46 fy } & \multirow{5}{*}{135} & \multirow{5}{*}{13.5} & 251,466 & 2.28 & 251,466 & 0 \\
\hline SHA- $80^{\circ}$ & & & & 253,742 & 2.23 & 253,742 & 2,276 \\
\hline SHA- $60^{\circ}$ & & & & 306687.1 & 2.10 & 306687.1 & 55,221 \\
\hline SHA- $45^{\circ}$ & & & & 341,763 & 2.14 & 341,763 & 90,297 \\
\hline SHA- $30^{\circ}$ & & & & 558,830 & 2.39 & 558,830 & 307,364 \\
\hline SHA- $10^{\circ}$ & 0.6 fy & 178 & 17.8 & $1,674,001$ & 1.65 & $3,837,200$ & $3,585,734$ \\
\hline
\end{tabular}


Table 4. Experimental program and test results of specimens with 30\% damage level

\begin{tabular}{|c|c|c|c|c|c|c|}
\hline $\begin{array}{l}\text { Specimen } \\
\text { symbol }\end{array}$ & $\begin{array}{c}\text { Fatigue } \\
\text { loading } \\
\text { level }\end{array}$ & $\begin{array}{l}\mathrm{P}_{\max } \\
(\mathrm{kN})\end{array}$ & $\begin{array}{l}\mathrm{P}_{\min } \\
(\mathrm{kN})\end{array}$ & $\begin{array}{c}\text { Fatigue life } \\
\text { (cycles) }\end{array}$ & $\begin{array}{l}\text { Fatigue life } \\
\text { Improvement } \\
\text { factor }\end{array}$ & $\mathrm{Nm}$ \\
\hline US-30-90 & & & & 25.995 & N/A & 0 \\
\hline US-30-80 & & & & 27,149 & N/A & 1,154 \\
\hline US-30-60 & 0.46 fy & 135 & 13.5 & 32,000 & N/A & 6,005 \\
\hline US-30-45 & & & & 41,119 & N/A & 15,124 \\
\hline US-30-30 & & & & 79,314 & N/A & 53,319 \\
\hline US-30-10 $10^{\circ}$ & & & & 402,033 & N/A & 376,238 \\
\hline SHD-30- & & & & 52,905 & 2.04 & 0 \\
\hline SHD-30- & & & & 54,544 & 2.03 & 1,639 \\
\hline SHD-30- & 0.46 fy & 135 & 13.5 & 64,579 & 2.02 & 11,674 \\
\hline SHD-30- & & & & 81,555 & 1.98 & 28,650 \\
\hline SHD-30- & & & & 129,496 & 1.63 & 76,591 \\
\hline SHD-30- & & & & 683,275 & 1.70 & 630,370 \\
\hline SHA-30- & & & & 66,442 & 2.56 & 0 \\
\hline SHA-30- & & & & 71,300 & 2.63 & 4,858 \\
\hline SHA-30- & 0.46 fy & 135 & 13.5 & 85,941 & 2.69 & 19,499 \\
\hline SHA-30- & & & & 118,372 & 2.88 & 51,930 \\
\hline SHA-30- & & & & 181,945 & 2.29 & 115,503 \\
\hline SHA-30- & & & & $1,203,575$ & 2.99 & $1,137,133$ \\
\hline
\end{tabular}


Table 5. Values of the ratio $\left(\mathrm{N}_{\mathrm{m}} / \mathrm{N}_{\beta=90}\right)$ of specimens with $10 \%$ damage level

\begin{tabular}{llllll}
\hline Specimen Type & \multicolumn{2}{l}{ Inclination angle } & & \\
\cline { 2 - 6 } & $10^{\circ}$ & $30^{\circ}$ & $45^{\circ}$ & $60^{\circ}$ & $90^{\circ}$ \\
\hline US & 20.06 & 1.12 & 0.44 & 0.32 & 0.00 \\
\hline SHD & 19.81 & 1.16 & 0.45 & 0.24 & 0.00 \\
\hline SHA & 14.26 & 1.22 & 0.36 & 0.22 & 0.00 \\
\hline Average & 18.04 & 1.17 & 0.42 & 0.26 & 0.00 \\
\hline
\end{tabular}


Table 6. Values of the ratio $\left(\mathrm{N}_{\mathrm{m}} / \mathrm{N}_{\beta=90}\right)$ of specimens with $30 \%$ damage level

\begin{tabular}{llllll}
\hline Specimen Type & \multicolumn{3}{l}{ Inclination angle } & & \\
\cline { 2 - 6 } & $10^{\circ}$ & $30^{\circ}$ & $45^{\circ}$ & $60^{\circ}$ & $90^{\circ}$ \\
\hline US & 14.47 & 2.05 & 0.58 & 0.23 & 0.00 \\
\hline SHD & 11.92 & 1.45 & 0.54 & 0.22 & 0.00 \\
\hline SHA & 17.11 & 1.74 & 0.78 & 0.29 & 0.00 \\
\hline Average & 14.5 & 1.75 & 0.63 & 0.25 & 0.00 \\
\hline
\end{tabular}

